\title{
DER FUND VON ADA
}

\author{
CSANÁD BÁLINT*-ÉVA GARAM** \\ * Forschungszentrum für Humanwissenschaften \\ der Ungarischen Akademie der Wissenschaften \\ Archäologisches Institut \\ Úri u. 49, H-1014 Budapest, Ungarn \\ balint.csanad@btk.mta.hu \\ ** Ungarisches Nationalmuseum \\ Múzeum krt. 14-16, H-1088 Budapest, Ungarn \\ garam.eva@hnm.hu
}

\begin{abstract}
Numerous finds, excavated from the probably isolated grave along the Lower Tisza, were taken to the Vojvođanski Muzej (Novi Sad, Serbia). The grave can be dated unambiguously to the second half of the $8^{\text {th }}$ century. Drawing a parallel between the silver cup and the $8^{\text {th }}$-century dish of the Nagyszentmiklós treasure has a considerable significance both for the chronologic and cultural identification of the latter, and for the Avar-Age chronology of tendril decoration with punched background as well. Accordingly, this decoration had been around already in the $7^{\text {th }}$ century, which is an equally important condition for the chronology of the late Avar Period, and especially for the research of the question of continuity between the middle and late periods. Keywords: Late Avar archaeology, the Nagyszentmiklós treasure, incised tendril decoration with punched background
\end{abstract}

\section{VORWORT}

Den Fund von Ada sah Cs. Bálint das erste Mal 1971, É. Garam wiederum fertigte 1981 im Laufe ihrer Studienreise durch Jugoslawien Aufzeichnungen über diesen Fund an. Von der silbernen Schale wurde die wissenschaftliche Welt offiziell in demselben Jahr auf der vom Archäologischen Institut der Ungarischen Akademie der Wissenschaften in Szeged veranstalteten internationalen Konferenz in Kenntnis gesetzt. ${ }^{1} 1975$ hielt sich Cs. Bálint erneut in Újvidék auf, um mit der mündlichen und schriftlichen Genehmigung von S. Nagy Aufnahmen und eine Beschreibung von dem Fund zwecks einer Veröffentlichung anzufertigen. ${ }^{2} \mathrm{Zu}$ diesem Zeitpunkt war sich S. Nagy bereits im Klaren darüber, dass seine Zeit, Energie und Interesse durch die Freilegung und Publizierung der Kirche von Dombó (Dubovac, Serbien), ein von ihm freigelegtes Denkmal von herausragender Bedeutung aus dem ungarischen Mittelalter, in Anspruch genommen sein würden. ${ }^{3}$ So begnügte er sich mit einer kürzeren Veröffentlichung des Fundes von Ada und der dort zum Vorschein gekommenen Schale. Während seiner zweiten Studienreise konnte Cs. Bálint auch Aufnahmen über die teilweise hier veröffentlichten Gürtelbeschläge von Újvidék-Csene (Novi SadČenej, Serbien) mit Erlaubnis von R. Bunardžić anfertigen lassen (Abb. 8) sowie das einige Jahre lang als Sensation

Die ursprüngliche Fassung dieses Aufsatzes konnte seinerzeit aus finanziellen Gründen nicht erscheinen. Wegen der besonderen Bedeutung des Fundes von Ada veröffentlichen wir die 2005 abgeschlossene Variante. Aus der Reihe der inzwischen erschienenen Publikationen sind die Folgenden hervorzuheben: B. M. SzŐKE: Egy avar kori indavirág. Késő avar kori övgarnitúra Zalaegerszeg-Ola, Új kaszárnya területéről (Eine awarenzeitliche Rankenblume). ZalaiMúz 10 (2001) 103-140; É. GARAM: Virágos palmetták és félpalmetták. Adatok az adai ezüsttálka keltezéséhez (Contribution to the origin of the silver plate of Ada. Floral ornaments and semi-palmettses - BlumenPalmette und Halbpalmetten. Beiträge zur Datierung der Silberschale von Ada). Arrabona 44/1 (2006) 151-164.

${ }^{1}$ NAGY 1972.

${ }^{2}$ Die Aufnahmen fertigte L. Sugár (Archäologisches Institut der Ungarischen Akademie der Wissenschaften) an. Auch an dieser Stelle danken wir ihm für seine Arbeit.

${ }^{3}$ S. NAGY: Dombó. Újvidék 1974. 
geltende Material des awarischen Gräberfeldes von Cséb (Čelarevo), ${ }^{4}$ das gerade zu dieser Zeit von R. Bunardžić freigelegt worden war, kennenlernen.

Dieser Aufsatz stellt eine späte Ehrenbezeugung der Tätigkeit von Sándor Nagy dar, der mehr als zwei Jahrzehnte hindurch, manchmal unter sehr schweren Bedingungen, begeistert für die frühmittelalterliche und mittelalterliche Archäologie der Woiwodina arbeitete. Ihm gebühren nicht nur die Anerkennung und der Dank der Forschung des einstigen Jugoslawiens bzw. des heutigen Serbien, sondern des gesamten Karpatenbeckens. Sándor Nagy starb 1995.

\section{BESCHREIBUNG DER FUNDE}

Im Sommer 1965 brachten Bagger bei Erdarbeiten auf dem Gelände der Ziegelfabrik in Ada (Serbien) archäologische Funde zutage. O. Brukner, derzeit Mitarbeiterin von Pokrajinski Zavod za Zaštitu Spomenika Kulture Vojvodine (Novi Sad), und S. Nagy, Mitarbeiter des Vojvođanski Muzej (Novi Sad), begaben sich zu dem Fundgelände, auf dem ein großes Durcheinander herrschte. Es war nicht daran zu denken, auch nur irgendwelche sachliche Informationen über die Fundumstände zu bekommen. Einige Wochen später besuchte S. Nagy abermals den Fundort. Zu diesem Zeitpunkt waren die Erdarbeiten mehrere Meter weiter fortgeschritten, und er stellte fest, dass neuere Funde oder Gräber nicht zutage gekommen waren. Die eingesammelten Funde werden im Vojvođanski Muzej (Novi Sad) aufbewahrt.

\section{Pferdegeschirr}

Schildförmige Beschläge (Abb. 1.1, 2), 2 St., aus Bronze gegossen, mit dem nicht durchbrochenen Anhänger in einem Stück gegossen. Der schildartige Teil der Beschläge ist mit einem Rahmen umgeben, das Feld durch eine parallel verlaufende Linie unterteilt. Am Rand und an der Trennlinie sind Kerbungen. An den unbeweglichen Anhängern sind III-förmige Motive, die kaum an die einstige Rankenverzierung erinnern. Die Beschläge stammen nicht aus ein und demselben Gussmuster, auffallend ist die unterschiedliche Verzierung der Anhänger: Am unteren Teil des sorgfältiger bearbeiteten Stückes ist das Muster besser zu erkennen. Die am Rand verlaufende Kerbung und die zur Befestigung der Niete dienenden Löcher sind ebenfalls unterschiedlich. Material und Technik der Beschläge scheinen übereinzustimmen und können Produkte derselben Werkstatt sein. An dem Beschlag besserer Qualität ist die Niete zum Befestigen erhalten geblieben, die durch zwei runde Plättchen aus Kupfer am Leder befestigt wurde. An diesem Beschlag sind einstige Bruchspuren zu erkennen.

Maß: B: $3-2,92 \mathrm{~cm}, \mathrm{H}: 3,34-3,29 \mathrm{~cm}, \mathrm{D}: 0,9-0,35 \mathrm{~cm}$.

Große, schildförmige Beschläge (Abb. 1.3, 4), zwei gegossene Beschläge, die zusammen mit dem durchbrochenen, unbeweglichen Anhänger gegossen sind. Das Material wurde mit viel Kupfer hergestellt, ausgezeichnet erhaltene Bronze, mit Spuren dicker Vergoldung. Die Beschläge sind glatt, unverziert, die Rückseite krustenartig. Das Muster der unbeweglichen Anhänger bilden einander zugewandte stilisierte Greifen(?)köpfe.

Maß: B: 2,65 - 3,35 cm, H: 4,75 cm, innere B: $1,6 \mathrm{~cm}$.

Kurze Riemenzunge (Abb. 1.5), sehr gut erhaltene, aus einem Glied gegossene Riemenzunge aus Bronze. Kurze, rechteckige Form, mit zwei erhöhten, runden Ösen. An dem gerippten Beschlagkörper sind Einkerbungen, die von dem Gussmuster stammen. In den Ösen zwei runde, flachköpfige Niete, die verhältnismäßig lang sind, L: $1,05 \mathrm{~cm}$. An der Rückseite der einen Niete ein rundes Plättchen aus Kupfer.

Maß: B: $2,3 \mathrm{~cm}, \mathrm{H}: 1,5 \mathrm{~cm}$.

Längere Riemenzunge (Abb. 1.6), gut erhaltenes, rechteckiges Gussstück aus Bronze mit viel Kupfer. Die Vorderseite ist glatt, unverziert, unter dem Rand verläuft eine Kehlung, die Rückseite ist krustenartig. Unter dem Rand sind drei Löcher, in zweien steckt der bronzene Niet, an der Rückseite befindet sich ein großes, rundes Plättchen.

$\mathrm{Ma}: \mathrm{B}: 3,2 \mathrm{~cm}$ (unter dem oberen Rand etwas hervorspringend), $\mathrm{H}: 3,3 \mathrm{~cm}$.

\footnotetext{
${ }^{4}$ Er gestattete auch die erneute Veröffentlichung der Gürtelbeschläge von Újvidék (Novi Sad)-Csene. Für seine Freundlichkeit danken wir ihm wiederum.
} 

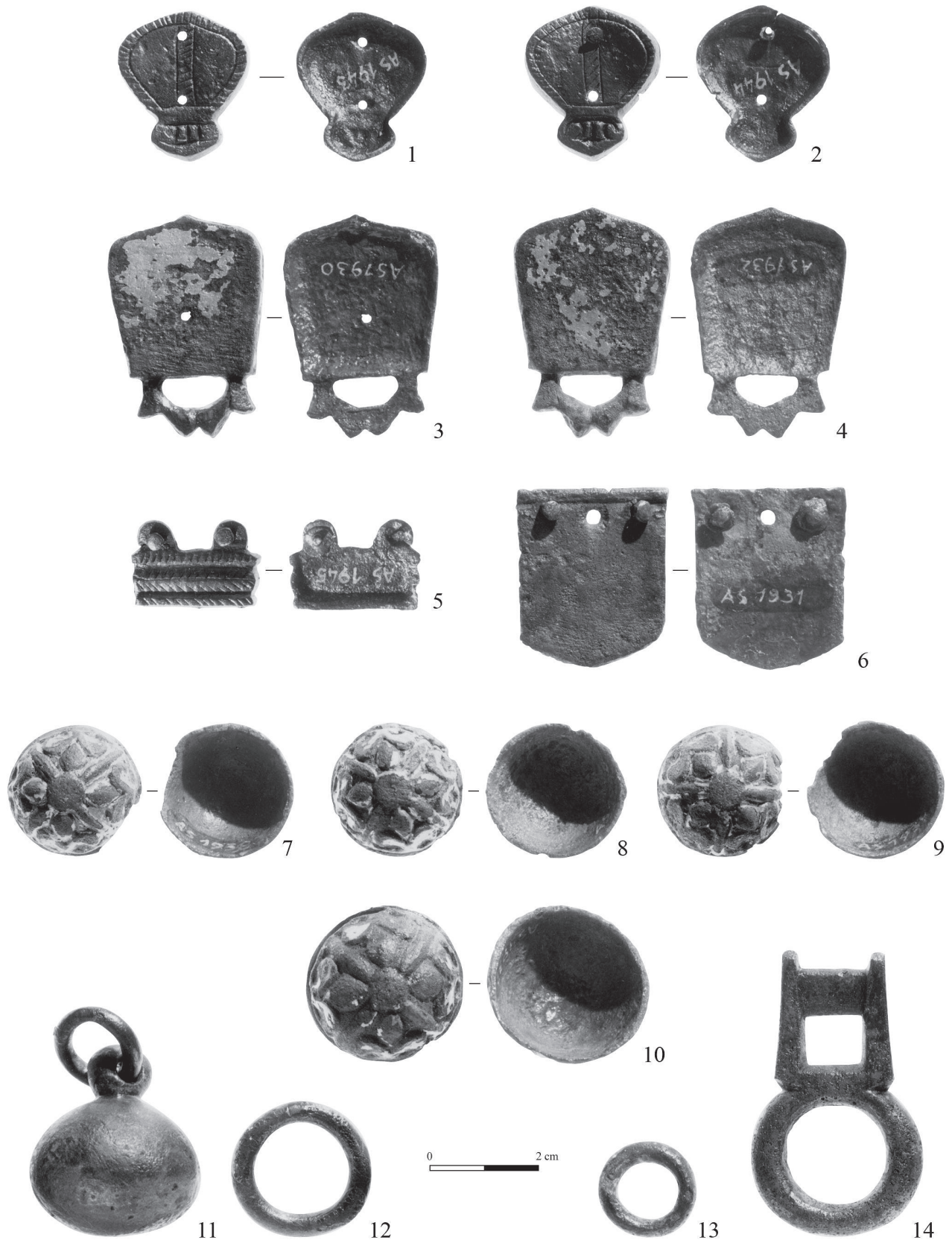

Abb. 1. Der Fund von Ada. 1-2: schildförmige Beschläge; 3-4: große, schildförmige Beschläge; 5: kurze Riemenzunge; 6: längere Riemenzunge; 7-10: konische Beschläge; 11: Morgenstern; 12-13: bronzene Ringe; 14: Ösenring

Konische Beschläge (Abb. 1.7-10), aus Bronze gegossene Stücke, die viel Kupfer enthalten, starke Vergoldung, die im Hintergrund des Musters besser erhalten geblieben ist. Die Oberfläche der kugelabschnittförmigen, konischen Beschläge ist viergeteilt, in den einzelnen Feldern sind tief eingravierte Palmetten mit Knospen und auseinanderragenden Blättern. Am unteren Rand der Beschläge verläuft eine kreisförmige Rille. Das Innere der Beschläge ist hohl, von der Befestigung sind keine Spuren mehr vorhanden. 3 St. gleichen Maßes, 1 St. ist größer. Maß: Dm: 2,9-3,4 cm, H: 1,9-2,2 cm. 


\section{Sattelzubehör}

Sattelbeschlag (Abb. 2.1), schmales, an den Enden stark gebogenes Kupferblech, fragmentarisch, unvollständig, die Löcher sind überwiegend paarweise angebracht, durch die das Blech an den vorderen Sattelbogen (von der vorderen Platte aus) angenietet wurde.

Maß: L: 15,6 cm, B: 1,7 cm, Lochdm: 0,15-0,2 cm.

Steigbügel (Abb. 2.2-3) aus Eisen mit breiter Sohle und rechteckiger Öse. Die parallel verlaufenden Schenkel sind im unteren Drittel breit geklopft. Die ungewöhnlich breite Sohle ist durch fünf vertiefte und in gleichmäBigem Abstand voneinander verlaufende Furchen verstärkt. In den Furchen sind in gleicher Höhe eine Reihe von Löchern. Von dem anderen Steigbügel sind nur zwei kleinere Fragmente übrig geblieben.

Maß: H: 18 cm, größte B: 11,7 cm, Schulterb: 10,6 cm, Ösenl: 3,4 cm, Sohlenb: 5,7 cm, Rippenb: 0,4 cm. Gurtschnalle (Abb. 2.3), rechteckige, große, intakte Eisenschnalle.

$\mathrm{Maß}: \mathrm{L}: 6 \mathrm{~cm}, \mathrm{~B}: 5,9 \mathrm{~cm}$.

Ösenring (Abb. 1.14), massiver Bronzering, der mit der rechteckigen, profilierten Öse in einem Stück gegossen ist. Guss von guter Qualität, ausgezeichnet erhalten.

Maß: L: 5,65 cm, B: 3,6 cm (äußere B), 2,2 cm (innere B), 2,5 cm (obere B), Reifend: 1,3 cm, Ösenteildm: $1,1 \mathrm{~cm}$.

Bronzener Ring (Abb. 1.12), Guss von guter Qualität, gut erhalten, im Inneren ungleichmäßig rund und dick. Maß: Dm: $3 \mathrm{~cm}, \mathrm{D}: 0,95 \mathrm{~cm}$, innerer Dm: 2,15 - 2,2 cm.

Bronzener Ring (Abb. 1.13), kleiner als der Vorige, Guss von geringerer Qualität, regelmäßig kreisrund. Maß: Dm: 2,25 - 2,3 cm; D: $1 \mathrm{~cm}$, innerer Dm: 1,5 cm.

\section{Waffen}

Lanzenspitze (Abb. 2.4)

Nach der Restaurierung sind heute nur noch zwei unkenntliche Stücke davon vorhanden. Der mündlichen Mitteilung von S. Nagy zufolge waren diese bereits vor der Restaurierung stark fragmentarisch. Mit Sicherheit konnte man nur feststellen, dass die Spitze mit einer Tülle versehen war und die Lanze ganz bestimmt keine Flügel hatte. Maß: L: $8,2 \mathrm{~cm}$ und $8 \mathrm{~cm}, \mathrm{~B}: 1,9 \mathrm{~cm}$ und $0,6 \mathrm{~cm}$.

Bogenknochen (Abb. 3)

Fast der vollständige Bestand an Versteifungsplatten aus Knochen von den Armen und der Mitte eines Bogens gelangte in ausgezeichnetem Zustand ins Museum. Die Bogenarme sind schmal und stark gebogen, ihre Breite entspricht dem aus der Awarenzeit allgemein bekannten Typ.

Maß: Bogenenden: L: $21 \mathrm{~cm}, 21 \mathrm{~cm}$ (fragmentarisch), 21,1 cm, $23 \mathrm{~cm}, \mathrm{~B}: 3,2 \mathrm{~cm}$, Griffteile: L: $17 \mathrm{~cm}$, $18,1 \mathrm{~cm}, 18,4 \mathrm{~cm}, \mathrm{~B}: 3,1 \mathrm{~cm}, 2 \mathrm{~cm}, 3,1 \mathrm{~cm}$, mittlere Versteifungsplatten: L: 11,6 cm, $12,2 \mathrm{~cm}, 14 \mathrm{~cm}, 15,7 \mathrm{~cm}$, B: $2,2, \mathrm{~cm}, 2 \mathrm{~cm}, 2,4 \mathrm{~cm}, 2,5 \mathrm{~cm}$.

Morgenstern (Abb. 1.11)

Gut erhaltene, massive, aus Bronze gegossene, leicht abgeflachte Kugel mit Öse von guter Qualität. An der Öse ein Ring, dessen Enden gut zusammengeschmiedet sind.

Maß: Dm: 3,4×3,55 cm, H (mit Öse): 4 cm, Ringdm: 2,2 $2,4 \mathrm{~cm}, \mathrm{D}: 0,9 \mathrm{~cm}$.

\section{Silberschale (Abb.4-5)}

Die ovale, an den Enden leicht abgerundete Schale wurde durch gleichmäßiges Treiben aus einem einzigen Silberblech angefertigt. Das Blech war ursprünglich Silber von guter Qualität, heute ist es nicht mehr in so gutem Zustand. Die Schale hat einen schmalen Rand, der annähernd rechtwinklig nach außen gebogen ist. Der Henkel ist eselsrückenartig und stark abgenutzt. Beim Schneiden der Platte war der Silberschmied nicht sehr auf Symmetrie bedacht, denn der Henkelbogen ist links etwas graziöser und länger als rechts. In der Mitte des Henkels ist ein Loch, das von einem Ornament umgeben ist. Der Rand des Lochs ist vollkommen glatt, an der Vorderseite neigt sich der 


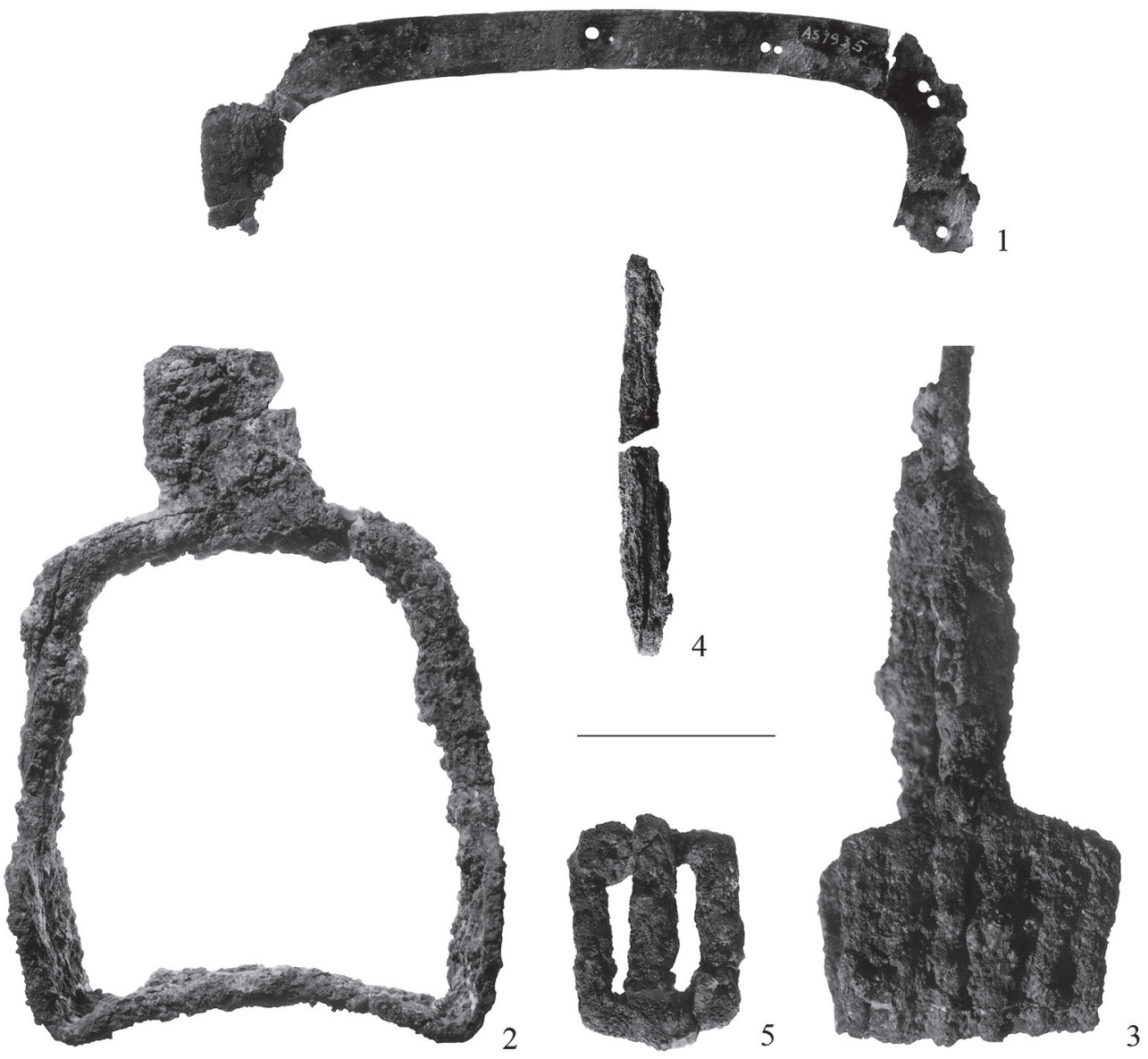

Abb. 2. Der Fund von Ada. 1: Sattelbogenbeschlag; 2-3: Steigbügel (Vorder- und Nebenseite); 4: Reste der Lanzenspitze; 5: Gurtschnalle

Einschnitt kaum bemerkbar nach innen, d. h. das Schneiden kann aus dieser Richtung vorgenommen worden sein. Der Henkel ist unregelmäßig rund und durch Niete mit leicht rundem Kopf (Dm: 0,3 cm) von außen fast gleich voneinander entfernt $(1,5 \mathrm{~cm})$ an die Schale befestigt. Die Spitzen der Niete wurden sorgfältig weggeklopft. Bei der Verzierung des Henkels hat der Schmied vorerst berechnet, wie viel der Schalenrand vom Henkel verdecken wird, so dass die das eigentliche Ornament rahmende, sehr regelmäßig verlaufende Linie sich nur an einer Stelle dem Rand nähert und ansonsten immer außerhalb desselben verläuft. Die am Rand verlaufende Linie und die Verzierung selbst wurden mit derselben - ziemlich stumpfen - Punze angefertigt. Die kontinuierliche und gerade Linienführung deuten auf eine sichere und geübte Handhabung. Die Punzenspitze, mit der der Hintergrund bearbeitet worden war, war röhrenartig und wurde häufig nur leicht eingeschlagen, demzufolge konnte das Innere des Punzeeisens nicht immer die zu bearbeitende Oberfläche erreichen. Der Schalenboden ist bootsartig gestaltet.

Maß: H: $12,3 \mathrm{~cm}, \mathrm{~B}: 17 \mathrm{~cm}$.

\section{BEWERTUNG DER FUNDE}

\section{Pferdegeschirr Beschläge}

Mit Ausnahme eines einzigen Beschlagtyps kann man aufgrund der Analogien und - wenn möglich - unter Berücksichtigung ihrer Lage im Grab von den gegossenen Bronzezierden des Fundes von Ada behaupten, dass diese 


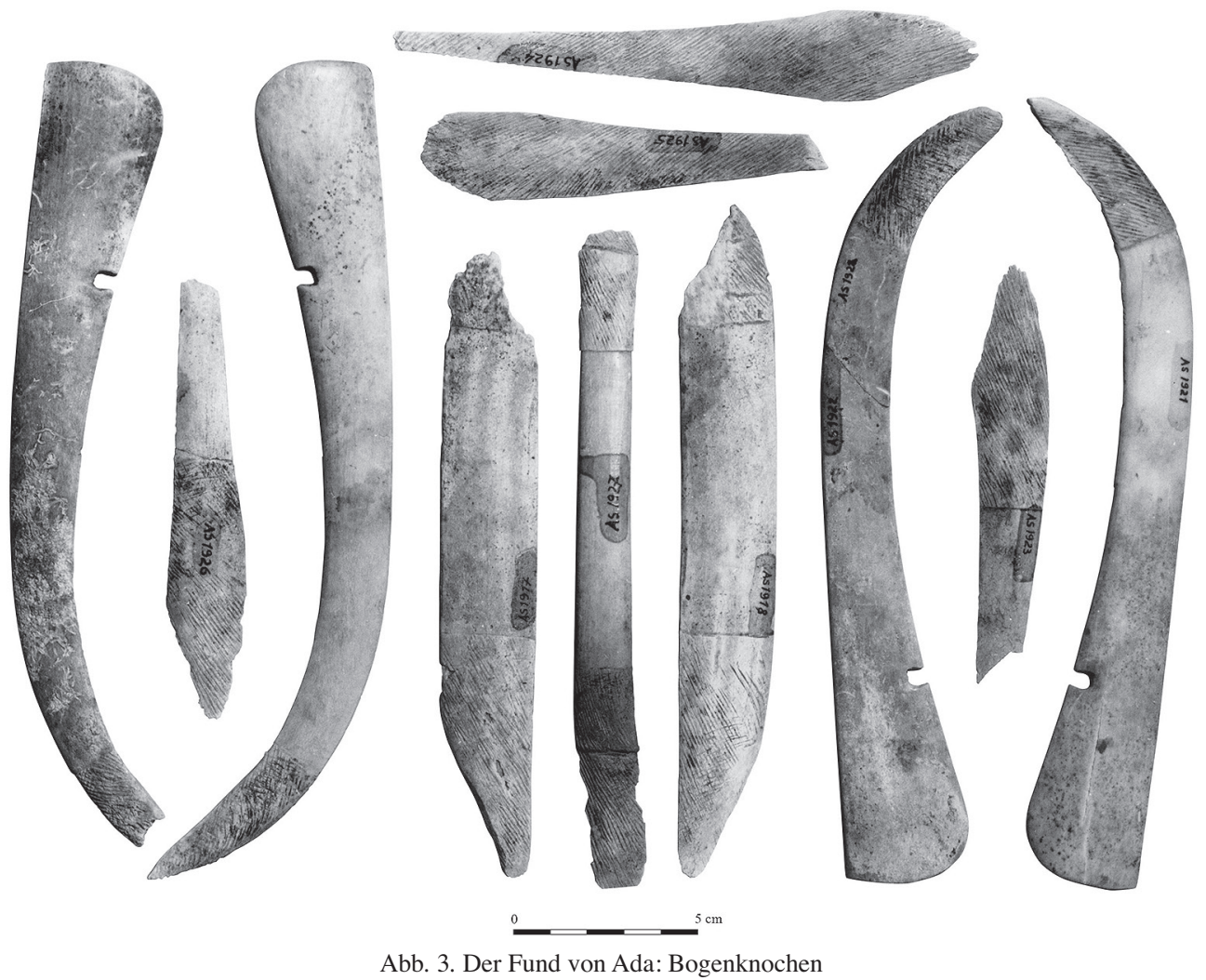

als Pferdegeschirrbeschläge gedient hatten. Da außerdem aus dem Grab noch Steigbügel, ein Sattelbogenbeschlag, eine Gurtschnalle und kleine Ringe aus Bronze zum Vorschein gekommen sind, ist es möglich, dass in vorliegender Zusammensetzung der Fund aus einem Pferdegrab stammt, dem - ebenfalls aufgrund von Parallelen - auch die Waffen des Pferdebesitzers oder wenigstens ein Teil davon (Lanze, Bogen, Morgenstern) beigegeben worden waren. Die beiden schildförmigen Beschläge können eher zu dem bestatteten Besitzer des Pferdes gehört haben, wie auch die silberne Schale. Pferdegrab oder Reitergrab mit Pferdebestattung - das ist hier die Frage, die wahrscheinlich nicht mehr entschieden werden kann.

Die Beschläge, die ins Museum gelangten, stellen fünf verschiedene Typen dar und sind in dieser Zusammensetzung in keinem einzigen anderen Fundensemble anzutreffen. (Die dieser am nächsten stehende Zusammensetzung - 4 Typen (a, b, d, e) - ist aus dem Fund von Gajár (Gajary, Slowakei) bekannt.) Da aber alle möglichen Kombinationen vorkommen, scheint die typologische Zusammengehörigkeit aller fünf Typen offensichtlich. Charakteristisch ist der gegossene Rand, was auch für den Großteil aller mit diesen in Verbindung zu bringenden Parallelen - besonders für die im nördlichen Teil des Karpatenbeckens gefundenen Stücke - kennzeichnend ist. (Die Beurteilung wird dadurch erschwert, dass die meisten Publikationen keine Nebenseite der Beschläge darstellen.) Die randgegossenen Riemenzungen - sowohl die gerippten als auch die glatten, unverzierten - wurden mit Hilfe eines an die Rückseite angebrachten dünnen Bronzeplättchens befestigt; in dem Fund von Ada fehlt jedoch diese Art Plättchen.

a) Schildförmige Beschläge mit unbeweglichem unteren Glied (siehe Katalog A1-7)

Hinsichtlich ihrer Form stimmen diese genau mit den aus der späten Awarenzeit bekannten schildförmigen Gürtelbeschlägen überein. Die Abweichung besteht darin, dass das untere Glied unbeweglich, mit dem oberen zusammen gegossen ist. In der späten Awarenzeit ist eine so puritane Verzierung der Gürtelbeschläge sehr selten; und dazu gehören auch die Beschläge von Ada. Was ihre Verzierung anbelangt, so stammt eine ihrer besten Analogien aus Komárom-Hajógyár Grab 1 (Kat.-Nr. A6), bei der - ähnlich den hier behandelten - die stilisierte Rankenverzierung des unbeweglichen Anhängers, aber mit graviert-gepunztem Muster versehenen Beschlag, an das III-förmige Muster des Anhängerteils von Ada erinnert. Die Lage dieses Beschlags, im Grab ist unbekannt, aber bei einem 


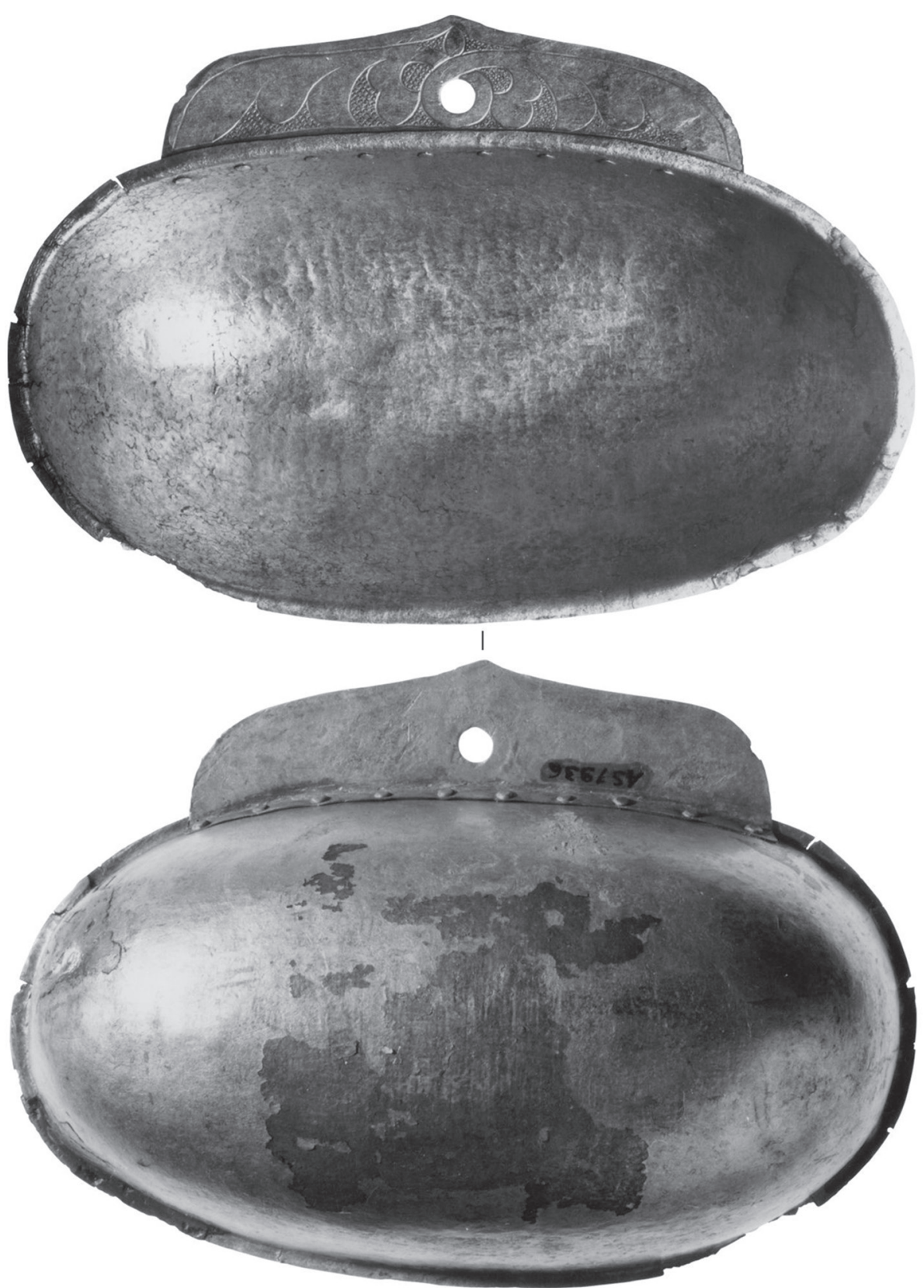

Abb. 4. Der Fund von Ada: Silbeschale (Blick von oben und von unten)

anderen, ähnlichen Beschlag aus einem Gräberfeld von Komárom (Gadóc, Grab 24, Kat.-Nr. A3 ) notierte der Ausgräber, dass dieser am Brustkorb des Pferdeskeletts gefunden worden war. So kann letzterer Beschlag sicher am Brustriemen befestigt gewesen sein. Eine andere Analogie kann in dem Fund von Gajár (Kat-Nr. A4) festgestellt werden. Über die Art und Weise der Benutzung des Beschlags stehen - da dieser ein Streufund war - keine Angaben zur Verfügung. Sicher wurde aber der Beschlag aus Újvidék-Csene (Abb. 8.1; Kat.-Nr. A9), der zusammen mit anderen Gürtelbeschlägen ins Museum gelangte, von seinem Besitzer am Gürtel getragen, denn aus diesem Grab kamen keine Zaumzeugbeschläge, überhaupt kein Pferdegeschirr ans Tageslicht. 
b) Größere, schildförmige, vergoldete Beschläge aus Bronze mit unbeweglichem, durchbrochenem Anhänger (siehe Katalog $B 1-11$ )

Analogien zu den großen, schildförmigen Anhängern kamen - insofern ihre Lage im Grab bekannt ist - am Hinterteil des Pferdes zum Vorschein. Man kann also annehmen, dass auch in Ada diese Art der Beschläge das Riemenzeug am hinteren Teil des Pferdes verzierte. Ihre Anzahl, 2 St., entspricht der in der späten Awarenzeit allgemein üblichen: Jeweils ein Stück zu beiden Seiten des Brust- und Hinterriemens.

c) Kurze, gerippte Riemenzunge mit erhöhten Ösen (siehe Katalog C1-15)

d) Gerade Riemenzunge mit gebogenen Enden (siehe Katalog D1-11)

Parallelen zu der mit Ährenmuster verzierten kleineren und der unverzierten größeren Riemenzunge kamen am Schädel, in der Gegend der Nackenwirbel, und einmal in der „Kreuzgegend“ eines Pferdes zutage. Aufgrund dieser Tatsachen kann man vermuten, dass mit der kleineren Riemenzunge irgendein Teil des Riemenzeuges am Kopf des Pferdes (Nase- oder Kinnriemen), mit der größeren wiederum entweder der Kinnriemen verschlossen oder der Sattel befestigt worden war.

e) Längliche, konische, vergoldete Bronzebeschläge mit Rankenverzierung

Infolge fehlender genauer Analogien ist es sehr schwer zu entscheiden, an welchem Teil des Zaumzeuges diese reich vergoldeten, konischen Beschläge gewesen sein könnten, sind doch die diesen in der Form am meisten ähnelnden Parallelen nicht aus einem Grab, sondern aus dem Streufund von Gajár bekannt. Konische Beschläge ähnlicher Größe, aber nicht vollkommen identischer Verzierung und Materials vom mittleren Teil der Phaleren stammen aus den jüngsten Pferdegräbern mehrerer Gräberfelder (Szob, Vörs, Zalakomár). Aus den drei verschiedenen Massen der Beschläge von Ada kann man darauf schließen, dass diese entweder die unterschiedlich dicken Riemen des Zaumzeuges verzierten (in diesem Fall kann man berücksichtigen, dass der Nasenriemen im Allgemeinen schmaler als der Längsriemen des Zaumzeugs ist) ist oder aber die kleineren Beschläge das Zaumzeug und der größere Beschlag - sicher zusammen mit dem fehlenden zweiten Stück - in der Mitte der eventuell zerfallenen Phalere gewesen sein könnte. Es ist sehr wahrscheinlich, dass von diesem Beschlagtyp ursprünglich mehrere in dem Grab vorhanden waren.

Die Analogien sämtlicher hier behandelten Beschläge stammen aus Fundensembles, die in die zweite Hälfte des 8. Jahrhunderts datiert werden können. Allerdings soll hinzugefügt werden, dass die obere zeitliche Grenze dieser Beschlagtypen unbekannt ist.

Was die Analogien der Pferdegeschirrbeschläge aus dem Fund von Ada anbelangt, so sind derartige Typen in zwei Regionen häufiger anzutreffen: Im heutigen Komárom und in der Umgebung von Újvidék, was - egal wie man diese Konzentrationen erklärt (politisches, Handels-, Werkstattzentrum?) - jedenfalls beachtenswert ist. Es sei noch erwähnt, dass diese Beschläge auch noch an einem Fundort in der Umgebung von Hernád zum Vorschein gekommen sind, während ihr Vorkommen in Mikulčice zeigt, dass ihr Gebrauch nicht ausschließlich für die Awaren kennzeichnend ist und noch bis in das 9. Jahrhundert hineinreicht. Betrachtet man ihre territoriale Verbreitung, kann festgestellt werden, dass diese Beschläge im größten Teil der östlichen Hälfte des Karpatenbeckens überhaupt nicht vorkommen: Von den hier behandelten Beschlagtypen stammt nicht eine einzige Parallele aus dem gesamten Gebiet zwischen Donau und Theiß, aus der Gegend des Nördlichen Mittelgebirges, aus der Großen Ungarischen Tiefebene und aus Siebenbürgen. Das ist in der späten Awarenzeit keine einmalige Erscheinung, schon früher wurde eine regionale Konzentration gewisser Gürtel- und Pferdegeschirrbeschläge bzw. deren Fehlen beobachtet. Das lässt aller Wahrscheinlichkeit nach auf eine Werkstattstätigkeit schließen. ${ }^{5}$ Die bei den Parallelen zu dem Fund von Ada festgestellte ungleichmäßige territoriale Verbreitung lässt darüber hinaus noch die Schlussfolgerung zu, dass die Beschläge aus einem bestimmten Grab keine Verbindung zu der Makroregion (d. h. die Große Ungarische Tiefebene), in die der Fundort (genauer: der dort Bestattete) unserer geographischen Ansicht nach gehört, aufweisen. Diese

${ }^{5}$ Vgl. G. Kiss: A Szombathely-Kőszegi úti avar lovassír. A későavarkori négy- és ötkaréjos lószerszámveretek. (Das awarische Reitergrab von Szombathely-Köszegi út. Die spätawarenzeitlichen vier- und fünfblättrigen Pferdegeschirrbeschläge). MFMÉ 1984/85-2, 451; KISS 1996, 139, Taf. 7; P. STADLER: Verbreitung und Werkstätten der awarischen Hauptriemenbeschläge mit Greifendarstellung. In: H. Friesinger-F. Daim (Hrsg.): Typen der Ethnogenese unter besonderer
Berücksichtigung der Bayern 2. Denkschriften der Österreichischen Akademie der Wissenschaften, Phil.-Hist. Klasse 204. Wien 1990, 337, Karte 4; J. ZÁBOJNÍK: Seriation von Gürtelbeschlaggarnituren aus dem Gebiet der Slowakei und Österreichs (Beitrag zur Chronologie des awarischen Kaganats). In: A. Ruttkay (Hrsg.): K problematike osídlenia stredodunajskej oblasti v včasnom stredoveku. Nitra 1991, 219-321. 

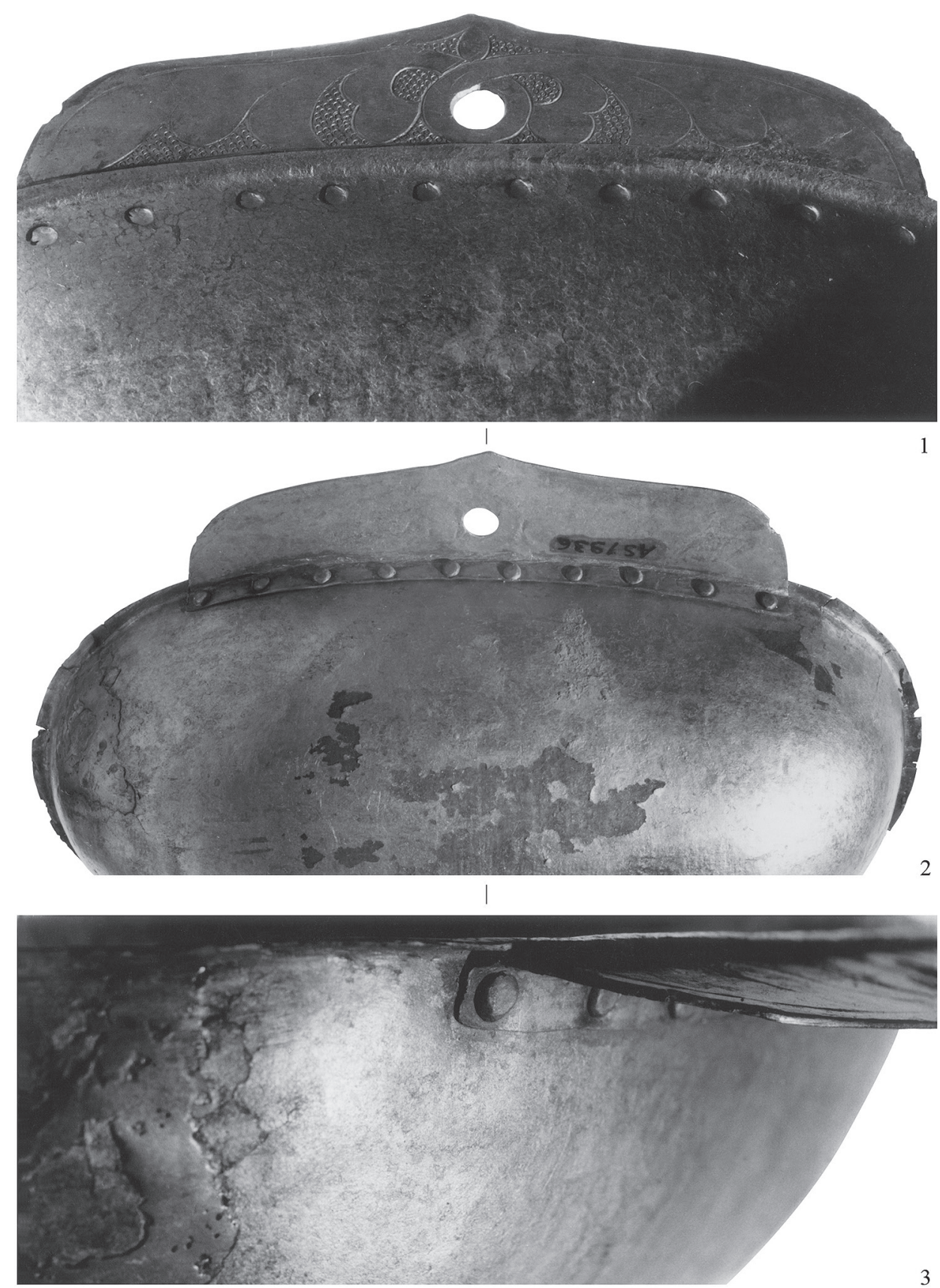

Abb. 5. Befestigung mit Nieten des Henkels der Silberschale von Ada

Angabe bestätigt auch die allgemeine Anschauung, dass die Verbreitung der Gegenstandstypen durchaus nicht immer der naturgeographischen Landschaftseinheit folgt, sondern vielmehr die Tätigkeit von Werkstätten und die Handels- und/oder politischen Verbindungen der Bevölkerung widerspiegelt.

Mit Rücksicht darauf, dass in dem Fund von Ada die Trense fehlt und anderes Pferdegeschirrzubehör ins Museum gelangte, ist es wahrscheinlich, dass der Teil um den Pferdeschädel herum bereits durchwühlt worden war, bevor die Experten an die Fundstelle gelangten, also nicht alle Beigaben für die Wissenschaft erhalten geblieben sind. 
Sattel

Von dem Sattel sind der vordere Sattelbogenbeschlag, die eiserne Gurtschnalle und zwei Steigbügel erhalten geblieben. Analogien zu den kleinen Bronzeringen aus Ada sind am „Kreuz des Pferdes“ und an der „Stelle des vorderen Sattelbogens“ in Grab 85 von Komárom-Hajógyár zu finden. Darum kann man annehmen, dass diese entweder auch zum Sattel gehörten oder aber - zusammen mit dem großen Ösenring - zum Aufhängen von Bogen und Köcher am Sattel dienten.

Der Sattelbogenbeschlag war ein an mehreren Stellen durchlochtes, gebogenes Kupferblech, das ursprünglich am unteren Bogen des vorderen Sattelbogens befestigt gewesen sein konnte. Form und Bogenlänge stimmen mit den bisher bekannten und gut messbaren spätawarischen, eisernen Sattelbogenbeschlägen überein. ${ }^{6}$ Von Letzteren ist schon seit Längerem bekannt, dass die kurzen, rechteckigen, zweiseitigen Beschläge den Sattelbogen zusammenhielten und die dem Sattelbogen folgenden Eisenbleche eine verzierende Rolle innehatten. ${ }^{7}$

In den breiten Gebieten zwischen Altai und Save waren die aus einem einzigen Eisenblech gefertigten, den vorderen Sattelbogen zu beiden Seiten zusammenhaltenden Satteleisen verbreitet. Alle diese Stücke stammen aus den 8.-9. Jahrhunderten und es stimmen nicht nur ihr Alter, sondern auch ihre Maße und typologischen Details überein. ${ }^{8}$ Es scheint so, dass zu diesen Fundtypen auch das Beschlagblech von Ada gehört, das aber nicht aus Eisen, sondern aus Kupfer ist, schmaler als diese ist und kein Gegenstück für die Rückseite hat. Das war offensichtlich eine einfachere Lösung und ohne jegliche Funktion, nicht so, wie bei den die beiden Seiten zusammenhaltenden Satteleisen aus Eisenblech. Das vorliegende Kupferblech konnte für den Sattelbogen nur eine sehr geringe Verzierung bedeutet haben und zum Zusammenhalten überhaupt nicht geeignet gewesen sein. (Es ist interessant, dass die Mehrheit der awarenzeitlichen Satteleisen aus dem Gebiet östlich der Theiß zum Vorschein gekommen ist. ${ }^{9}$ ) Die landnehmenden Ungarn des 10. Jahrhunderts ${ }^{10}$ hatten auch Sattel, deren vorderer Bogen mit Silberblech unregelmäßiger Form verziert war. Derartige Sattel waren auch im Nordkaukasus ${ }^{11}$ verbreitet. Bei dem Sattel von Ada kann kaum von einer Verzierung die Rede sein und noch weniger von einer praktischen Bestimmung. Oder ist es möglich, dass die Suche nach einer Funktion nur unserer modernen Anschauung zu eigen ist und in der Awarenzeit selbst eine minimale Verzierung, überhaupt ein Metallblech am Sattelbogen, schon von Bedeutung war?

Das Steigbügelpaar (siehe Katalog F1-15) vertritt einen gar seltenen Typ. Die ungewohnt breite und durch mehrere Rippen gegliederte Sohle verleiht dem Paar die typologische Eigenartigkeit. Diese Sohle reicht ganz bis zum unteren Drittel der Schenkel, wo dann in den Rippen zwei Reihen winziger Löcher sind. Auch in der Benutzung zeigt sich ein Zug, der nicht als allgemein bezeichnet werden kann: Mit Rücksicht auf die sehr geringe Anzahl muss - wenn auch vorsichtig - die Aufmerksamkeit darauf gelenkt werden, dass in den authentischen Grabungen nur jeweils ein einziges Stück in einem Grab war. Die Schenkelform dieses Steigbügeltyps ist übrigens mit den bekann-

${ }^{6}$ Kiss 1996, 121, Taf. 7; 140-143, Taf. 8-11; EgerRépástetô s. BÁLINT 1979, Pl. 17.

${ }^{7}$ É. GARAM: Pferdegräber des awarenzeitlichen Gräberfeldes von Tiszafüred. Angaben der spätawarischen Pferdebestattungen. Alba Regia 23 (1987) 75.

${ }^{8}$ Tujachta, Kurgan 2, Ausgrabung von S. V. Kiselëv im Jahre 1937 (unveröffentlicht), Gosudarstvennyj Istoričeskij Muzej, Moskva, Inv.-Nr. 79601 (die Untersuchung des Funde ermöglichte Cs. Bálint T. Puškina, 1978); Verchnee Saltovo (unveröffentlicht), Gosudarstvennyj Ėrmitaž, Sanktpeterburg, Inv.-Nr. 2423/183, 184 (die Untersuchung ermöglichte Cs. Bálint A. T. Pokrovska, 1978); Majaki, Katakombe 30: V. S. FLËRov: Majackij mogil'nik. In: S. A. Pletnëva (Hrsg.): Majackoje gorodišče. Trudy sovetsko-bolgaro-vengerskoj èkspedicii. Moskva 1984, Abb. 2; Dmitrievo Grab 135: PletNËvA (1989) 89, ris. 43; Zagreb-Kruge, Grab 4, Abb. 6.1 des vorliegenden Aufsatzes (die Untersuchung und Veröffentlichung der in Zagreb von Cs. Bálint gemachten Zeichnung hat $1971 \nmid Z d$. Vinski erlaubt), vgl. BÁlint 1979, Pl. 16.1; Bolgarka: S. GuCalov: Pogrebenie oguzopečenežskogo vremeni v kurgane Bolgarka I (Aktjubinskaja oblast'). In: V. B. Kovalevskaja (red.): Novoe v srednevekovoj archeologii Ev- razii. Samara 1993, 94, ris. 10; Dyrso: A. V. DMITRIEv: Mogil'nik Djurso - Etalonnyj pamjatnik drevnostej V-IX vekov. In: T. I. Makarova-S. A. Pletnëva (red.): Arheologija. Krym, Severo-vostočnoe Pričernomor'e i Zakavkaz'e v èpochu srednevekov'ja IV-XIII. veka. Moskva 2003, 258, tab. 91. 12-14.

${ }^{9}$ Kiss 1996, 143, Taf. 11.

${ }^{10}$ I. DiENES: Les Hongrois conquérants. Budapest 1972, 30, Fig. 8; BÁLINT 1979, 17; I. Fodor (ed.): The Ancient Hungarians. Budapest 1996, 50, 95, Fig. 22, 101, Fig. 34.

${ }^{11}$ A. A. GAVRILOVA: Mogil'nik Kudyrgè kak istočnik po istorii altajskich plemën. Moskva-Leningrad 1965, 73. - Die Funde von Zmejskaja stanica sind nur soweit als Parallele zu den erwähnten landnahmezeitlichen Funden zu betrachten, als dass bei diesen die Bleche ebenfalls an den Sattelbogen befestigt waren. Abweichungen wiederum bestehen in deren Verzierung. Auch wenn diese unverziert sind, wurden sie doch ausgesprochen mit dem Ziel der Verzierung zwischen die geschnitzten Muster des Sattelbogens eingefügt; vgl. V. A. KuZNECOV: Zmejskij katakombnyj mogil'nik (po raskopkam 1957). Materialy po Archeologii i Drevnej Istorii Severnoj Osetii 1. Ordžonikidze 1961, tab. VI, XI.9-15. 
ten Steigbügeln der Saltovo-Majackoe-Kultur und denen aus der späten Awarenzeit identisch. Wegen der weiten lokalen Verbreitung, lohnt es sich, die Aufmerksamkeit auf diese ungewöhnlichen Züge zu richten.

Unseres Wissens sind Steigbügel dieses Typs bisher nur noch aus vier weiteren Fundorten zutage gekommen. Von diesen ist der in Grab 14 des Gräberfeldes von Brodski Drenovac (Kroatien) neben dem gezäumten Pferd zum Vorschein gekommene Steigbügel seit Langem bekannt. (Das andere Stück ist einem anderen Typ zuzuordnen: Es gehört zu den in der späten Awarenzeit weit verbreiteten. ${ }^{12}$ Besondere Aufmerksamkeit verdient allein die ausgezeichnete Qualität des Eisens, aus dem dieser Steigbügel gefertigt ist; Abb. 6.2.) Die Sohle dieses Steigbügels ist leicht konkav und durch sechs Rippen gegliedert, die zu beiden Seiten ganz bis zum Ende der Sohle am unteren Drittel der Schenkel reichen (H: 17,4 cm). Im unteren Drittel der Schenkel sind in den Rillen zwischen den Rippen in zwei waagerecht verlaufenden Reihen runde Löcher. Über die Breite der Sohle gibt die Grabbeschreibung keine Auskunft. Diese konnte aber aufgrund des eine Viertelseite ausmachenden Fotos mit Hilfe eines bildanalysierenden Computerprogramms errechnet werden: ${ }^{13}$ Sie beträge $5,1 \mathrm{~cm}$.

In zwei Gräbern des Gräberfeldes von Gadóc wurden Steigbügel dieses Typs gefunden. In Grab (Pferdegrab) 15 war - wie auch in einem anderen Grab dieses Gräberfeldes - nur ein Steigbügel, dessen Form in jeder Hinsicht mit dem in der späten Awarenzeit verbreiteten Typ identisch ist. Ein individueller Zug ist, dass an der Sohle vier Rippen sind. Die Maße dieses Steigbügels: H: $17 \mathrm{~cm}$, B: $12 \mathrm{~cm}$, die anhand der Grabbeschreibung und veröffentlichten Skizze errechnete Breite der Sohle: $4,7 \mathrm{~cm} .{ }^{14}$ Aus Grab 24 desselben Gräberfeldes kam ein Steigbügel in sehr fragmentarischem Zustand zum Vorschein; so ist auch die davon angefertigte Skizze. ${ }^{15}$ Aufgrund Letzterer beträgt die mit Hilfe des oben bereits erwähnten analysierenden Computerprogramms errechnete Sohlenbreite 5,3 cm.

Den dritten Fundort der awarenzeitlichen Steigbügel, deren Sohle mit mehreren Rippen verziert war, stellt das Grab 51 des Gräberfeldes von Pitvaros dar, wo ebenfalls ein einziger Steigbügel ans Tageslicht kam. Seine Sohle ist breit $(5,5 \mathrm{~cm})$ und mit fünf Rippen verziert. Die über diesen Fund berichtende Autorin datiert das Grab aufgrund einer dreigliedrigen Stabperle an das Ende des ersten Drittels des 9. Jahrhunderts. ${ }^{16}$ Sie meint, dass das Pferdegeschirr selbst - aufgrund der Beschläge „wahrscheinlich zusammen mit dem Pferd“ (? Cs. B. - É. G.) ein Geschenk - ,von irgendwoher aus dem Nordwesten, aus dem Donaugebiet“ (?!) stamme. ${ }^{17}$

Der vierte Fundort ist das bisher unveröffentlichte Gräberfeld von Vörs, unter dessen in Kaposvár ausgestellten Funden É. Garam den aus Grab 468 stammenden Steigbügel mit breiter Sohle (B: min. $9 \mathrm{~cm}$ ) fand. An der Sohle sind vier Rippen, in deren Inneren an der Stelle, wo sich Schenkel und Sohle treffen, Durchlöcherungen sind: ein kreisrundes, ein rechteckiges und wieder ein kreisrundes Loch.

Breite, manchmal noch breitere als die bisher erwähnten Steigbügelsohlen können auch in anderen spätawarischen Funden nachgewiesen werden. (Zum Beispiel in Grab 8 des Gräberfeldes von Lukácsháza-Hegyaljadülö; B der Steigbügelsohle: 5,5-6 cm: ${ }^{18}$ Grab 162 und Grab 166 aus Dunacséb; Sohlenb: 5,5 cm; ${ }^{19}$ siehe Katalog F3). Diese haben aber alle nur eine einzige Rippe. Ähnliches ist auch aus vielen anderen Regionen Europas bekannt; unproportional breite Steigbügelsohlen kommen aus den Jahrhunderten um die Jahrtausendwende vielerorts vor, nur haben diese alle nicht mehr als eine Rippe.

Es ist wichtig festzustellen, dass über das Gewohnte hinausgehende breitere Sohlen in den osteuropäischen Steppen überhaupt nicht vorkommen, der Gebrauch solcher Steigbügel bei den Awaren also nicht östlichen Ursprungs ist. ${ }^{20}$

12 Vinski-Gasparini-Ercegović-PaVlović 1958, 156, Taf. XIII. 2. - Die später von diesem Steigbügel veröffentlichten Zeichnungen stammen leider alle aus dieser Publikation und wurden nicht anhand der Untersuchung des ursprünglichen Gegenstandes angefertigt; vgl. J. KovaČEvić: Avarski kaganat. Beograd 1977, 117, Fig. 60, rechts oben; MRKOBRAD 1980, Taf. CXXXIX.6.

${ }^{13}$ Für die Hilfe F. Gyulais danken wir.

${ }^{14}$ ČILINSKÁ 1982, 385, Taf. XIV.30.

${ }^{15}$ Ibidem 388, Taf. XVII.2, 36. H: $160 \mathrm{~cm}$, B: 12,4 cm.

${ }^{16}$ Laut freundlicher mündlichen Mitteilung von B. M. Szőke waren bekannterweise bereits im 8 . Jahrhundert bei den Awaren aufgekommen.

${ }^{17}$ BENDE 1998, 204

${ }^{18}$ Kiss 1996, 110, 135, Taf. 3.10-11.
${ }^{19}$ Bunardžıć 1979, 45, Taf. IV.3; idem 1985, Kat.-Nr. 418, Fig. 36, rechts unten (unnummeriert).

${ }^{20}$ Die Steigbügel des 8.-11. Jahrhunderts vom Gebiet Deutschlands, Böhmens und Mährens sowie Russlands sind typologisch für unsere Frage uninteressant, genauso die aus den 10.-12. Jahrhunderten vom Gebiet Skandinaviens, Polens und Litauens; vgl. STEIN 1967, 85, 416, Liste 19; A. N. KIRPIČNIKOv: Snarjaženie vsadnika i verchovogo konja na Rusi IX-XIII vv. Svod Archeologičeskich Istočnikov E1-36. Moskva 1973; J. ANTAVICIUS: Balno kilpos Lietuvoje X-XIV. Lietuvos TSR Mokslu Akademijos Darbai, Seria A. Vilnius 1976, Taf. 1.69-81; A. PEDERSEn: Similar finds - different meanings? Some preliminary thoughts on the Viking-Age burials with riding equipment in Scandinavia. In: C. Kjeld Jensen-K. Høilund Nielsen (eds): Burial and Society. The Chronological and Social Analysis of Archaeological Burial Data. Aarhus 1997, 179, Fig. 8; 

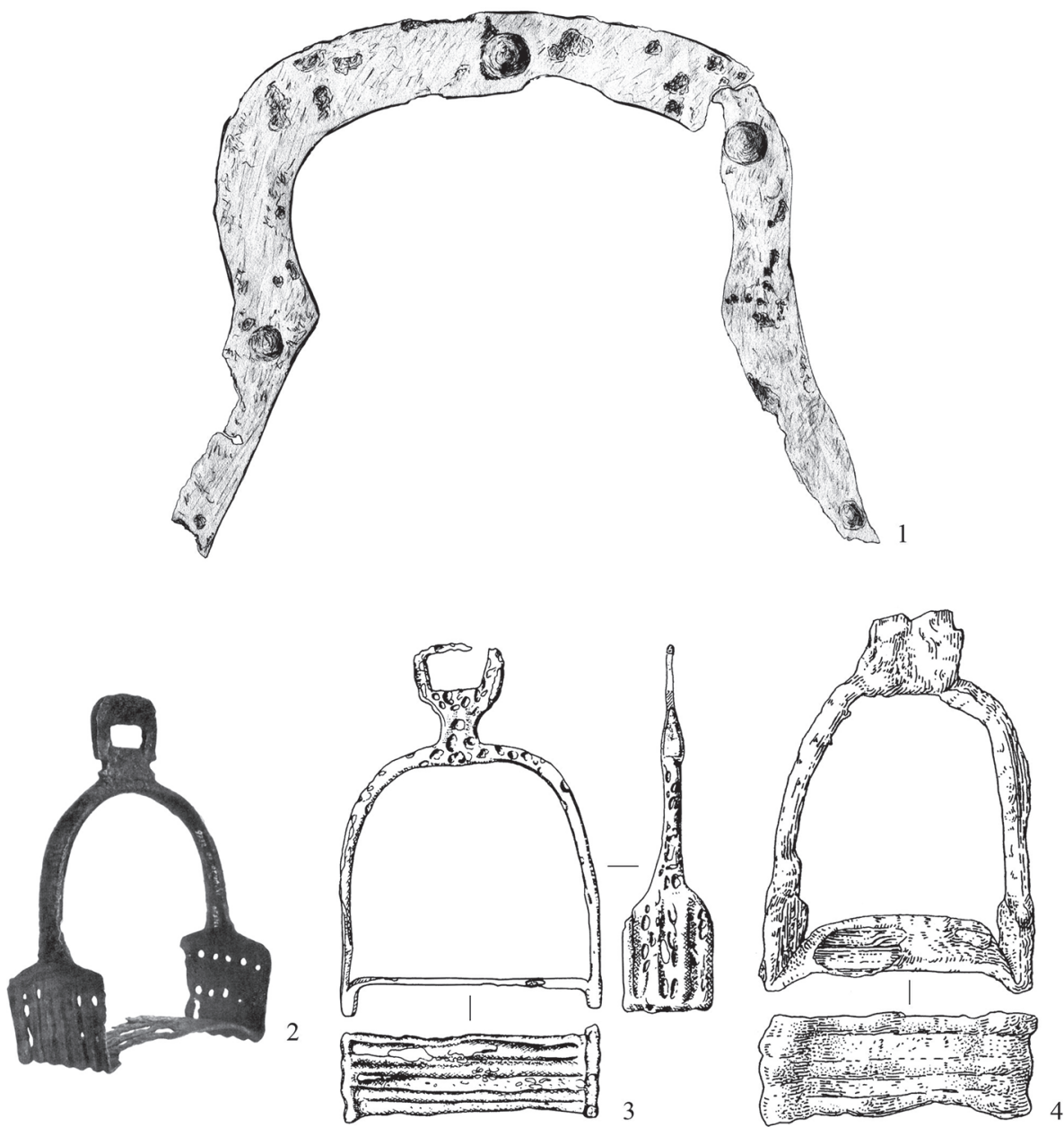

Abb. 6. 1: Sattelbogenbeschlag von Zagreb-Kruge; 2: Steigbügel aus Brodski Drenovac; 3-4: Kraków-Nowa Huta

Unter den mitteleuropäischen Funden findet man - mit Ausnahme eines Fundes aus Südpolen - keinen, der zu den Steigbügeln aus Ada - und zu den oben erwähnten verwandten Exemplaren - eine gute Parallele bilden könnte. Darum ist es informativ, einige Steigbügel aus Polen näher zu untersuchen.

Der eine in Grube M-2, Nr. 6b/62 des Fundortes Kraków-Nowa Huta, Mogila freigelegte Steigbügel ist gerade und hat eine verhältnismäßig breite Sohle $(4,5 \mathrm{~cm})$ mit zwei Rippen $(A b b .6 .3){ }^{21}$ Die in der ursprünglichen Veröffentlichung vorgeschlagene Datierung (zweite Hälfte des 10.-11. Jahrhunderts) ist offensichtlich ein Irrtum, denn die Autorin ging davon aus, dass die in Nowa-Huta gefundenen Steigbügel Parallelen zu den von ihr aus den erwähnten Jahrhunderten bekannten ungarischen Steigbügeln seien. Die Begründung dieser Feststellung kann mit einem kurzen Blick überprüft werden und bedarf keiner Widerlegung. Man kann diesen Steigbügel ganz offensichtlich nicht als Parallele zu denen aus der ungarischen Landnahmezeit betrachten; der stammt eigentlich aus einer

A. RUTTKAY: Waffen und Reiterausrüstung des 9. bis zur ersten Hälfte des 14. Jahrhunderts in der Slowakei II. SIA 24 (1976) 353-356; R. TUREK: Prachovské skály na usvite dejín. Praha 1946, 148; idem: Čechy na usvite dejín. Praha 1963, Fig. 15; J. Vignatiova: Snarjaženie vsadnika i verchovogo konja iz raskopok Bržeclav-Pogansko. PliskaPreslav 3. Sofia 1981, 88, Taf. 5.10a-c, 9a-c; W. Swietoslawski: Strzemiona sredniowieczne z ziem Polski (Medieval stirrups from Polish territories). Łódz 1990, 30, Fig. 16; 37, Fig. 18; Z. Mechurova: Třmeny, a jíne současti sedla z časné strdovékého obdobi (Die Steig- bügel und andere Sattelbestandteile aus dem Frühmittelalter). ČMM 68 (1983) 61-89.

${ }^{21}$ R. HACHULSKA-LEDWOS: Wczesnosredniowieczne strzemiona z Nowej Huty-Mogily (Étriers du haut Moyen Age de Nowa Huta-Mogila). MatArch 6 (1965) 117-126; idem: Wczesnosredniowieczna osada w Nowej Hucie - Mogile (An early medieval village at Nowa Huta-Mogila). MatArchNH 3. Kraków 1971, 191, 192, 205, 210; Zoll-AdamiKowa 1992, 301, Abb. 3.f. 
früheren Periode. Da aus dem Karpatenbecken keine genauen Analogien zur Verfügung stehen, ist es nicht geringer schwierig, den anderen Vorschlag zu akzeptieren, der die erwähnten Steigbügel aus Südpolen an die Wende von der mittleren zur späten Awarenzeit datiert. ${ }^{22}$ Der zusammen mit den Steigbügeln zutage gekommenen „Knüpfer“ aus Knochen bietet uns keinen entsprechenden chronologischen Anhaltspunkt; auf keinen Fall darf man aber diesen Fund in so enge zeitliche Grenzen datieren. H. Zoll-Adamikowa, die das Fundensemble als Zweite bewertete, war sich darüber klar, dass das Vorkommen letzteren Gegenstandes im Grab eher für das 6.-7. Jahrhundert als für die späteren Jahrhunderte charakteristisch ist. Man darf aber auch den Fund von Zagreb-Kruge nicht außer Acht lassen, der wahrscheinlich an Anfang des 9. Jahrhunderts datiert werden kann und in dem ebenfalls ein derartiger „Knüpfer" zum Vorschein gekommen war. ${ }^{23}$ Außerdem spricht für eine von Z. Kurnatowska vorgeschlagene spätere Datierung des Fundes von Nowa Huta auch der andere dort gefundene Steigbügeltyp, der tatsächlich den spätawarenzeitlichen und überhaupt nicht den Steigbügeln aus dem 6.-7. Jahrhundert nahe steht (Abb. 6.4). Demnach sind wir mit der Meinung einverstanden, nach der der Steigbügel von Nowa Huta als spätawarenzeitlich betrachtet wird, ${ }^{24}$ dem aber hinzugefügt werden soll, dass er nicht als spätawarischer Typ bezeichnet werden kann.

Die die Funde von Zagreb und Kraków aufarbeitenden Autoren konnten im Zusammenhang mit den von ihnen veröffentlichten Steigbügeln keine relevanten Parallelen nachweisen. Sie beriefen sich immer auf die ansonsten gut bekannten spätawarischen Steigbügeltypen aus dem 10.-11. Jahrhundert. Diese weichen aber - wie wir erneut darauf hinweisen möchten - von der Typologie der hier behandelten Steigbügel vollkommen ab. Zu alledem ist ein Großteil der erwähnten Steigbügel aus dem 10.-11. Jahrhundert geographisch und kulturell von den hier behandelten zu weit entfernt. ${ }^{25}$ Außerdem beachteten die erwähnten Kollegen nicht, wie eigenartig die Sohle, die Gestaltung der Rippen bei den von ihnen publizierten Steigbügeln ist. Vergleicht man die Steigbügelsohlen aus Zagreb und Kraków mit den spätawarenzeitlichen, so ist tatsächlich eine gewisse entfernte Verwandtschaft aufzuzeigen. Das kommt in der geraden Sohle und in der Schulterbildung im oberen Teil der Schenkel und bei den Exemplaren um die Jahrtausendwende ebenfalls in der geraden, breiten Sohle zum Ausdruck, soweit ist es also begründet, über eine Parallelität zu sprechen. All das beeinflusst aber unserer Meinung nach die typochronologische Einordnung der hier behandelten Steigbügel nicht wesentlich, denn es ist ja nur davon die Rede, dass die erwähnten Merkmale (gerade, fallweise breite Sohle, Schenkel mit Schulterbildung) nicht nur in einer engeren Periode und Region verbreitet sind.

Ähnliche Steigbügel mit breiter Sohle findet man in Südosteuropa auch. In einem in der südöstlichen Ecke des Karpatenbeckens zutage gekommenen Eisendepotfund gab es unter anderen auch zwei Steigbügel. ${ }^{26}$ Der eine war birnenförmig, mit gerader Sohle, ohne Öse, was für den vorliegenden Fall an sich uninteressant ist. Die Öse des anderen Steigbügels war quadratisch, die Schultern waren gerade, die Sohle ebenfalls, sie war aber außerordentlich breit $(7,3 \mathrm{~cm})$ und reichte an den Seite bis zur Mitte der Schenkel (Abb. 7.1). Es ist bekannt, dass die frühmittelalterlichen landwirtschaftlichen Geräte und Eisendepotfunde im Allgemeinen schwer zu datieren sind. Der Verfasser der Monographie über die südosteuropäischen landwirtschaftlichen Geräte übernahm diese Aufgabe zuerst gar nicht, ${ }^{27}$ man kann aber den Fund von Dragoslovani aufgrund der Keramik vom Typ Dridu eindeutig ins 9.-10. Jahrhundert datieren.

Ein anderer Steigbügel mit einer überdurchschnittlich breiten Sohle kam in Kosovopolje, Mazedonien ebenfalls aus einem Metalldepotfund zum Vorschein $(A b b .7 .2){ }^{28}$ Das Alter dieses Fundes kann am besten aufgrund der zahlreichen Steigbügel aus der ungarischen Landnahmezeit festgelegt werden, und zwar mit dem 10. Jahrhundert. Diese Datierung kann vielleicht noch dadurch präzisiert werden, dass einer der dort gefundenen 14 Steigbügel

${ }^{22}$ ZolL-ADAMiKowa 1992, 305, Abb. 5.14

${ }^{23}$ Siehe Katalog F12.

${ }^{24}$ J. POLESKI: Kleinpolen im 8.-10. Jahrhundert. Bemerkungen zu den Beziehungen zwischen Kleinpolen und Böhmen, Mähren, Slowakei und Ungarn. In: D. Čaplovič-J. Dorul'a (eds): Central Europe in $8^{\text {th }}-10^{\text {th }}$ Centuries. Bratislava 1997, 19, Abb. 3.14.

25 Jotov 1987, 94. Seiner Meinung nach existieren in Bulgarien keine genauen Parallelen. Unter den awarischen Funden erwähnt er die Steigbügel von Mártély und Keszthely als Analogien. Seine Literaturangaben stellen die bekannten Arbeiten von A. Ruttkay und A. N. Kirpičnikov dar, obwohl darin Steigbügel ähnlichen Typs überhaupt nicht vorkommen.
${ }^{26}$ M. Comşa-Gh. Constantinescu: Depozitul de unelte şi arme din epocă feudală tîmpurie descoperit la Dragoslovani (jud. Vrancea) (Dépôt d'outils et d'armes de la haute époque féodale découvert à Dragosloveni, département de Vrancea). SCIV 20 (1969) 433, Fig. 5.3-4.

${ }^{27}$ J. HenNING: Südosteuropa zwischen Antike und Mittelalter. Schriften zur Ur- und Frühgeschichte 42. Berlin [Ost] 1987, 122, Nr. 141.

${ }^{28}$ T. JANAKIEvSKI: Kale, s. Streževo-Bitolsko. MacAA 6 (1980) 104, Taf. 5a. 
nicht zu dem im 10. Jahrhundert bei den Ungarn allgemein verbreiteten und im Laufe des gesamten Jahrhunderts benutzten birnenförmigen Typ gehört, sondern der allgemein angenommenen typochronologischen Bestimmung nach zu dem im letzten Viertel des 10. Jahrhunderts in Ungarn verbreiteten Steigbügeltyp mit Schultern. Damit zusammen ist auch die Tatsache zu bewerten, dass in diesem Fund auch ein Steigbügel war, dessen Typ aufgrund der langen Ösen eindeutig den frühawarenzeitlichen Steigbügeln zugeordnet werden kann. Bisher ist es aber niemandem aufgefallen - und hierzu gehört auch Cs. Bálint, ${ }^{29}$ der die Ähnlichkeit dieses Typs mit denen aus der Awarenzeit betonte -, dass die breite und gerippte Sohle dieses Steigbügels eindeutig von dem im 6.-7. Jahrhundert benutzten Typ abweicht. Diese Art Sohle ist in frühawarischer Zeit tatsächlich unbekannt. Beide Züge der Sohle (gestiegene Breite und die Rippe) dieses Steigbügels kommen - wenigstens im Karpatenbecken - erst in der späten Awarenzeit auf. Betrachtet man die langen Ösen des Steigbügels etwas genauer, kann man bemerken, dass er nur aus typologischer Sicht den frühawarischen Steigbügeln zugeordnet werden kann, in Wirklichkeit aber nicht mit diesen übereinstimmt, da die Öse des Steigbügels von Straže niedriger und breiter ist, als die aus dem 6.-7. Jahrhundert. Darum sind wir der Meinung, dass dieser Steigbügel - trotz der Ähnlichkeit dieses Typs mit den awarenzeitlichen Steigbügeln - dem aus dem Fundensemble von Kosovopolje nicht fremd gegenübersteht, kein „Altstück“ war, sondern sich chronologisch in diesen einfügt.

Eine byzantinische Steigbügeldarstellung sollte hier unbedingt erwähnt werden. Auf dieser ist es sehr gut zu sehen, dass die in Seitenansicht schräg dargestellte Sohle eindeutig und auf beachtenswerte Weise breit ist. Die textilhistorische Forschung ist sich darin einig, dass das bekannte Seidenstück aus Mozac byzantinischen Ursprungs ist und aus dem 8. Jahrhundert stammt. ${ }^{30}$

Derartige Steigbügel kommen - unseres Wissens - außerhalb des Karpatenbeckens ausschließlich in zwei bulgarischen Fundorten vor. Nun muss die grundlegende Frage entschieden werden, was bei diesem Vorkommen wesentlich ist: Dass derartige Steigbügel überhaupt auf dem Territorium Bulgariens vorkommen ${ }^{31}$ oder dass außerhalb des Karpatenbeckens insgesamt nur in zwei Fundorten auf dem Balkan gefunden wurden? Leider können wir wegen der geringen Zahl der Fundorte und der derzeitigen Unsicherheit hinsichtlich der Datierung der bulgarischen Funde keine Stellung zu dieser wesentlichen Frage nehmen.

Der eine Fundort liegt in der Dobrudscha:: ${ }^{32}$ In Božurovo kamen vier Steigbügel mit einer derartigen Sohle ans Tageslicht (Abb. 7.3-6). ${ }^{33}$ Diese können unter Berücksichtigung verschiedener Gesichtspunkte in je zwei Untertypen unterteilt werden: aufgrund ihrer Ösengestaltung (breit, hoch, trapezförmig oder kleiner, viereckig), des Bogens ihrer Schenkel (unregelmäßig kreis- oder annähernd regelmäßig kreisförmig) und aufgrund ihrer geraden Sohle oder leichten Wölbung am Treffpunkt von Sohle und Schenkel. Die am Schenkel erhöhte Sohle ist verschiedenartig (oben gebogen - viereckig) und unterschiedlich hoch. Auch die Anzahl der Rippen ist unterschiedlich (5-6-7 an der Zahl). Insoweit man es anhand der veröffentlichten Skizzen beurteilen kann, gibt es bei einigen Sohlen in den Vertiefungen - ähnlich der von Ada - eine Lochreihe, bei einem anderen wiederum sind die Vertiefungen in den beiden oberen Dritteln durchgebrochen. Gemeinsam ist diesen Steigbügeln, dass sie durch ihre breite, mehrfach gerippte Sohle in ein und dieselbe typologische Gruppe gehören. Sie wurden ins 9.-10. Jahrhundert datiert.

Der andere Fundort in Bulgarien ist Dibič. Von hier stammt ein breiter, gerippter Steigbügel, der unveröffentlicht, aber im Nationalmuseum in Sofia ausgestellt war (1998). Dieser ist denen aus Božurovo ähnlich gestaltet. Eine erwähnungswerte Abweichung bedeutet allein die größere Breite der Sohle, was sich auch in der großen Zahl

${ }^{29}$ BÁLINT Cs.: A 9. századi magyarság régészeti hagyatéka.
${ }^{30}$ Von der allgemein bekannten und reichen Literatur dieses Seitenbruchstücks siehe M. MARTINIANI-REBER: Soieries sassanides, coptes et byzantines $\mathrm{V}^{\mathrm{e}}-\mathrm{XI}^{\mathrm{e}}$ siècles. Inventaire des collections publiques françaises 30. Paris 1986, 109-111, No. 96; A. MuthEsıus: Byzantine Silk Weaving AD 400 to AD 1200. Vienna 1997, 175, M 34. Vom Gesichtspunkt der awarischen und der archäologischen Steppenforschung siehe bei Cs. BÁLINT: Byzantinisches zur Herkunftsfrage des vielteiligen Gürtels. In: Cs. Bálint (Hrsg.): Kontakte zwischen Iran, Byzanz und der Steppe im 6.-7. Jahrhundert. VAH 9. Budapest 2000, 120-121.

${ }^{31}$ Durch ihre freundliche mündliche Mitteilung bestärkten uns Lj. Dončeva-Petkova und M. Inkova (Sofia), wir danken ihnen dafür.
32 Jotov 1987, 93-95.

${ }^{33}$ Der Autor, der die Steigbügel von Božurovo veröffentlichte, beruft sich auf das Steigbügelpaar, das in der Umgebung von Russe, in dem Dorf Krasen aus einem durchwühlten Grab ans Tageslicht gekommen war, als den Vorigen in Bulgarien allein ähnlich. Das trifft allerdings nur für die Gestaltung der Ösen und Schultern zu, für die Sohlen nicht. Der Typ der Steigbügel von Krasen - und auch die Sohle - stimmt nämlich mit den aus der späten Awarenzeit gut bekannten Steigbügeln überein. Die eine Sohle ist gerade und gewohnt breit, in ihrer Mitte zieht sich eine Rippe entlang, die andere ist konkav und hat keine Rippe; siehe V. DimOVA: Frühmittelalterliches bulgarisches Pferdegeschirr und Waffen in einem Grabfund bei Krasen. In: V. Georgiev et al. (Hrsg.): Studia in honorem Veselini Beševliev. Sofija 1978, 382-386. 

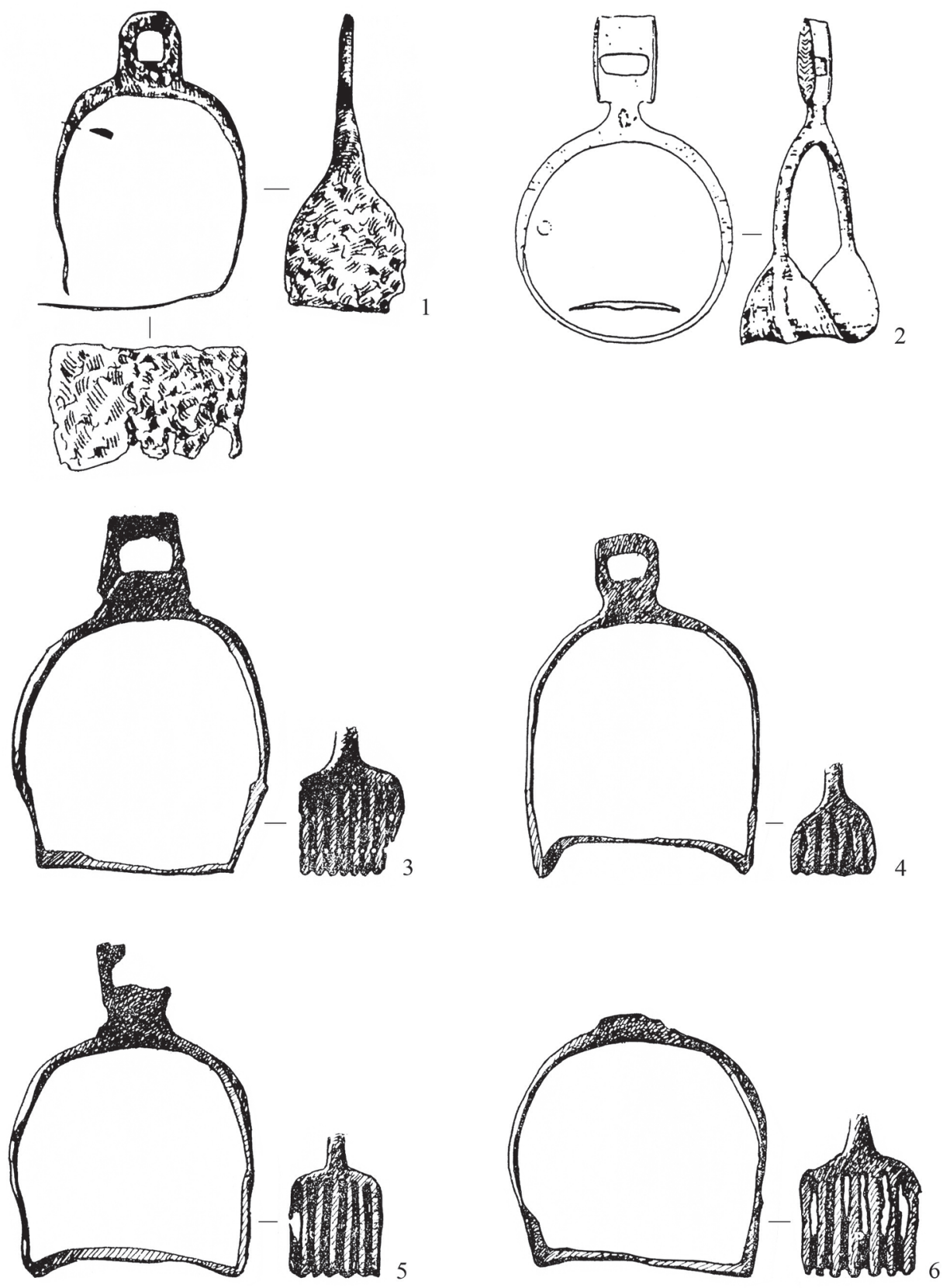

Abb. 7. Steigbügel mit breiter Sohle aus Südosteuropa: 1: Dragoslovani; 2: Kosovopolje; 3-5: Božurovo

der Rippen (sieben Stück) widerspiegelt. Löcher sind in diesen nicht zu erkennen. Hinsichtlich seines Alters gibt es nur den Anhaltspunkt, dass zusammen mit dem Steigbügel auch eine große, viereckige, gegossene Schnalle aus Bronze ins Museum gelangte. Ähnliche Steigbügel sind aus einem frühmittelalterlichen Gräberfeld in Bosnien, aus einem Grab mit einem Kinderskelett, dessen Alter nicht genau bestimmt werden kann, ${ }^{34}$ aus Bulgarien aus dem 10. Jahrhundert ${ }^{35}$ und aus dem Karpatenbecken aus Grab 3 des landnahmezeitlichen Gräberfeldes von Gádoros be-

${ }^{34}$ N. MiLetić: Nekropola u selu Mihaljevicima kod Rajlovca (Nécropole du village de Mihaljeviči près de Rajlovac. Résultats des fouilles ultérieures). GZM, Arheologija 1960/61, Taf. III.1.
${ }^{35}$ St. STANILov: Starobălgarski remačni ukrasi ot Nacionalnija Arheologičeski Muzej. Raskopki i Proučvanija 22. Sofia 1991, 55, Taf. I.4. 
kannt. ${ }^{36}$ Mit großer Wahrscheinlichkeit kann man also behaupten, dass die beiden in Bulgarien zum Vorschein gekommenen Steigbügel jünger als die aus dem Karpatenbecken sind.

Wenn man versucht, die Steigbügel vom Typ Ada zu datieren, sollte die Frage beantwortet werden, ob die geringe Zahl dieses Steigbügeltyps eine chronologische Erscheinung wäre oder man diese Verbreitung und Benutzung eher als eine kulturelle Eigenheit betrachten kann. Die zur Verfügung stehenden Angaben erlauben unseres Erachtens keine begründete Entscheidung.

Es ist fraglich, ob es bei so geringer Anzahl der Funde möglich ist, Schlussfolgerungen über ihre territoriale Verbreitung zu ziehen. Es gibt zwei Möglichkeiten.

a) Man könnte die Tatsache als beachtenswert bezeichnen, dass von den fünf Fundstellen drei in der westlichen Hälfte des Karpatenbeckens liegen. Das verringert die Möglichkeiten, dass man den allgemeinen Gebrauch dieses Steigbügeltyps in das 9. Jahrhundert datieren kann (in diesem Jahrhundert und in dieser Region war nämlich schon eine andere materielle Kultur verbreitet, die gut bekannt ist) und dass man diesen - mit Rücksicht auf die beiden Fundorte in Bulgarien - für vom donaubulgarischen Ursprung halten könnte, auf ein Minimum. Betrachtet man die zurzeit bekannten merowingischen Steigbügel aus dem 8. Jahrhundert, ${ }^{37}$ können wir zur Folgerung kommen, dass der Steigbügeltyp von Ada nicht aus Westeuropa stammt. ${ }^{38}$

b) Man könnte ihr Vorkommen auch so auslegen, dass der aus Gadóc allein in der nördlichen Hälfte des Karpatenbeckens von den fünf Grabfunden zum Vorschein gekommen ist, die anderen im südlichen Teil. Diese Lage erlaubt uns - mit Verweis auf die Parallelen aus Bulgarien - eine andere Annahme der kulturellen Wirkung vorauszusetzen. Da die Wahrscheinlichkeit, die westlichen Einflüssen würden Bulgarien umgehen, weitaus geringer ist, als in umgekehrter Richtung, erscheint die Möglichkeit von Einflüssen aus Südosteuropa (Byzanz?, Bulgarien?) nach dem Karpatenbecken wahrscheinlicher. Noch einmal betont, dass solche Funde zurzeit in sehr kleiner Anzahl bekannt sind und die aus Bulgarien sogar schwer zu datieren sind, ist unsere obige Argumentierung tatsächlich nicht unanfechtbar. Bei der Untersuchung der Ursprungsfrage bietet trotzdem der Umstand, dass Funde ähnlichen Typs in Westeuropa fehlen, einen Ausgangspunkt, genauso die Steigbügeldarstellung von Mozac. So könnte man vermuten, dass die breite Steigbügelsohle wohl aus Byzanz stammen könnte. Die aktuelle Forschungslage lässt zu, die Steigbügel vom Typ Ada bis auf Weiteres als ein in die zweite Hälfte der späten Awarenzeit datierbares Charakteristikum zu betrachten.

\section{WAFFEN}

Unter den Waffen des Reiters befanden sich - aufgrund der erhalten gebliebenen Funden - eine Lanze, ein Reflexbogen und ein Morgenstern.

Was den Typ der Lanze anbelangt, so kann man sich - da die Lanze sehr fragmentarisch ist - allein auf die Beobachtungen bei ihrer Auffindung stützen. Es ist nur bekannt, dass sie eine Spitze hatte und keine Flügel. Sicher gehört sie zu dem späten Typ der spätawarenzeitlichen Lanzen, für den eine lange, schmale Klinge charakteristisch ist. ${ }^{39}$ Aufgrund anderer Beobachtungen (Grab 94 von Kassazsebes, Grab 87 von Komárom-Hajógyár, Gräber 994, 1142 von Tiszafüred) ist es möglich, dass die Lanze auch hier in der Nähe des Pferdeschädels gelegen hatte, d. h. die Lanze bei der Bestattung mit der Spitze zum Kopf des Pferdes gerichtet neben dieses gelegt worden war.

Fast der gesamte Bestand an Versteifungsplatten von den Armen und der Mitte des Reflexbogens ist bekannt, sie sind in ausgezeichnetem Zustand erhalten geblieben. Die Bogenarme sind schmal und stark gebogen, auch ihre Breite entspricht der in der späten Awarenzeit allgemein üblichen.$^{40}$ Von den Reitergräbern, die als Parallele herangezogen werden können, wurden in drei Gräbern Bogenknochen und in zwei Pfeilspitzen beobachtet.

${ }^{36}$ Cs. BÁLINT: Südungarn im 10. Jahrhundert. StudArcha 11. Budapest 1991, 40, Taf. V.23.

${ }^{37}$ Vgl. STEIN 1967, 85, 416, Liste 19.

${ }^{38}$ Seiner freundlichen mündlichen Mitteilung nach hält es auch N. Gossler, der eine Zusammenfassung über die mittel- und südosteuropäischen Steigbügel aus dem 9.-11. Jahrhundert anfertigte, für ausgeschlossen, dass die Steigbügel vom Typ Ada westeuropäischen bzw. deutschen Ursprungs wären.
${ }^{39}$ Über die Typen der Lanzenspitzen siehe GARAM 1995, 349-350; neulich G. CsIKY: Avar-Age Polearms and Edged Weapons Classification, Typology, Chronology and Technology. Leiden-Boston $2015,68-151$.

${ }^{40}$ Über diesen Gegenstandstyp wurde noch keine typochronologische Analyse angefertigt. 

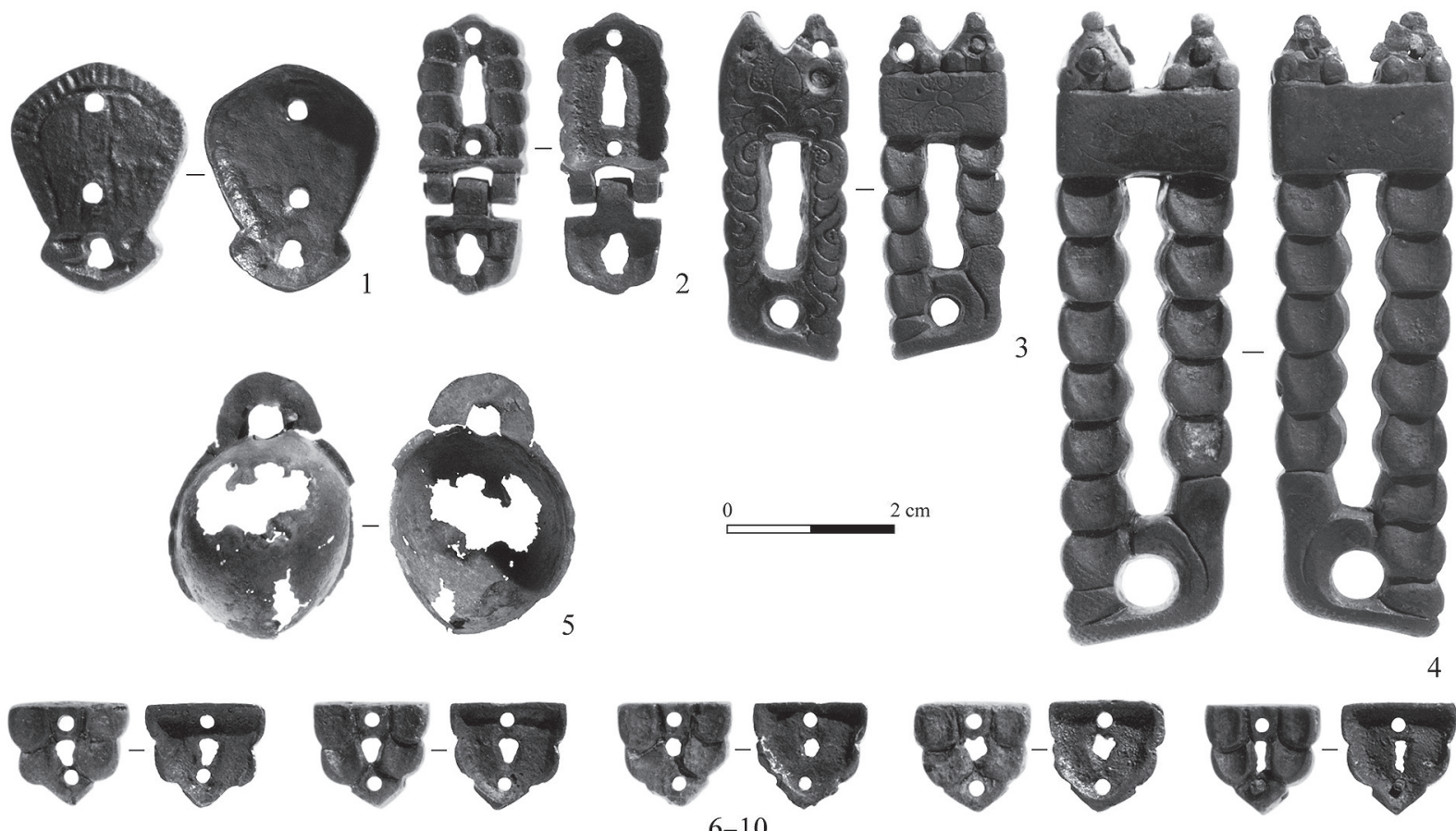

Abb. 8. Gürtelbeschläge aus Novi Sad-Čenej

Bemerkenswert ist, dass Pfeilspitzen und eiserne Köcherbeschläge nicht ins Museum gelangten.

Morgenstern. Ein unikaler Gegenstand aus diesem Fund ist eine massive, gegossene, bronzene Kugel mit Öse, an der noch ein kleinerer, geschlossener Ring aus Bronze hängt. Dieser bekam bei der Erstveröffentlichung die Bezeichnung „Lassoende“; ${ }^{41}$ demnach wäre die Funktion der Bronzekugel identisch mit der einer Bola. Letztere ist aber eine massive Kugel, die an einem langen Lederriemen befestigt ist und zum Einfangen der Pferde dient: Mit einem gezielten Wurf wickelt sich die Leine um ein Bein des Pferdes und hindert das Tier so am Laufen. L. Kovács lenkte jedoch unsere Aufmerksamkeit darauf, dass dieser Gegenstand wohl ein Morgenstern sein soll. ${ }^{42}$ É. Garam hat sich mit diesem Gegenstandstyp in einem anderen Aufsatz befasst, wonach sämtliche Parallelen aus der frühmittelalterlichen Steppe Eurasiens stammen. ${ }^{43}$

\footnotetext{
${ }^{41}$ BÁLINT 1989, 185, Abb. 83.5.

${ }^{42}$ Für seinen freundlichen Ratschlag danken wir ihm auch auf diesem Wege.

${ }^{43}$ É. GARAM: Avar kori csont ostor- vagy korbácsvégek és ostorbuzogány (Awarenzeitliche Knochenpeitschen oder Karbatschenden und Peitschenkeulen). ComArchHung 1998, 109-128. Östliche Parallelen siehe z. B. A. V. KRYGANOv: Kisteni saltovo-majackoj kul'tury Podon'ja (Bludgeons of the Saltovo-Mayak culture in the Don basin). SA 1987/2, 67; idem: Aziatskie elementy v vooruženija
}

rannesrednevekovych vostočnoevropejskich kočevnikov. In: Ju. S. Chudjakov-Ju. A. Plotnikov (red.): Voennoe delo drevnego i srednevekovogo naselenija Severnoj i Central'noj Azii. Novosibirsk 1990, 76; O. V. Komar-V. I. Pioro: Kurgany chozars'kogo čašu na Luganščyni. Vita antiqua 2. Kyjiv 1999, 157, tabl. 2.10. - G. Kubarëv hält den Letzteren aufgrund ähnlicher Funde in Sibirien für Peitschenenden; für seine freundliche mündliche Mitteilung danken wir ihm auch auf diesem Wege. 
Die ovale, flache Schale mit gebogenem Henkel ${ }^{44}$ ist nicht nur für den Fund von Ada, sondern für die gesamte awarenzeitliche Archäologie ein Fund von einmaliger und herausragender Bedeutung. Ihre enge Verwandtschaft mit der Schale Nr. 8 von Nagyszentmiklós war auf dem ersten Blick klar. ${ }^{45}$

Die Schale wurde aufgrund der Abnutzungsspuren aller Wahrscheinlichkeit nach lange Zeit hindurch benutzt. Diese Spuren bieten die Möglichkeit, Schlussfolgerungen auf die Art der Benutzung der Schale zu schließen. Worauf deuten nun die Abnutzungsspuren?

a) Aufgrund des Abnutzungs- und Brüchigkeitsgrades des Schälchenrandes kann man darauf schließen, dass es aller Wahrscheinlichkeit nach zum Trinken benutzt wurde.

b) Das Loch ist oben, an dem zum Henkel gerichteten Rand stärker geneigt und ist abgenutzter. Das kann ein Zeichen dafür sein, dass das Schälchen an einer schmalen, dünnen Schnur oder an einem Riemen aufgehängt aufbewahrt wurde.

Daraus kann man schließen, dass die Benutzung des Schälchens mit Gebrauch irgendeiner Flüssigkeit im Zusammenhang gestanden haben muss: Entweder wurde damit etwas abgemessen oder ausgeschenkt, oder aber es wurde daraus getrunken - das aber immer nur mit einer einzigen Bewegung einen Moment lang. Für eine sogar kürzere Zeit dauernden Aufbewahrung war es ungeeignet. Wir können annehmen, dass das Gefäß nach Benutzung hängend aufbewahrt worden war.

Was das Material, die Form und Verzierung der Schale von Ada anbelangt, ist das verwandte Exemplar aus Nagyszentmiklós die bisher einzige bekannte Parallele aus dem awarenzeitlichen Fundmaterial. Ihr besonderer Wert besteht nicht allein darin, dass endlich eine dem Gefäß aus Nagyszentmiklós sehr nahe stehende Analogie bekannt wurde, sondern gerade die mit der Schale zusammen zum Vorschein gekommenen anderen Gegenstände sind es, die dieser einen besonderen wissenschaftlichen Wert verleihen. Die erwähnten Gegenstände sind nämlich ziemlich gut zu datieren, und diese Tatsache stellt der Forschung, die sich bei dem Schatz von Nagyszentmiklós bisher ausschließlich auf ferne typologische Daten stützen konnte, eine besonders wertvolle Hilfe dar.

Lange war es allgemein bekannt, dass die typologisch naheste Analogie zu der Schale von Ada in dem Schatz von Vrap zu finden ist. ${ }^{46}$ Von den Metallgefäßen des Schatzes aus Albanien sind vier Schalen mit Henkel typologisch mit der Schale aus Nagyszentmiklós und der aus Ada verwandt; die Ähnlichkeit mit diesen ist aber weitaus geringer als die zwischen den beiden Letzteren. Die drei goldenen und die eine silberne Schale aus Vrap sind nämlich rund oder kaum oval und tiefer als die beiden aus dem Karpatenbecken. Außerdem sind ihre gebogenen Henkel kürzer, breiter und an zwei Stellen durchgelocht, ihre Wandung wiederum ist weitaus stärker. Von den goldenen Schalen aus Vrap hat nur eine verzierten Henkel, an dessen Vorderseite vertiefte Ranken vom sog. Typ Vrap sind; an der Rückseite gibt es gravierte auseinanderragende Halbpalmetten. An der Wandung und am Boden der silbernen Schale von Vrap gibt es Kanneluren, außerdem weicht dieses Exemplar auch in der Form des Henkelbogens von den anderen Schalen des Schatzes ab.

Aufgrund dieser Unterschiede gelangt man zu der Feststellung, dass es zwischen den beiden Schalen aus dem Karpatenbecken und den vier aus Albanien nur eine typologische Verwandtschaft besteht, insofern man alle - von anderswo bisher in dieser Periode unbekannten - Schalen in die Gruppe der Schalen mit flachem Henkel einreihen kann. Da die Ranken des Schälchens mit verziertem Henkel auf keinen Fall als ethnospezifisch angesehen

\footnotetext{
${ }^{44}$ Die bisherigen Bezeichnungen, auch in Zusammenhang mit ihrer Analogie von Nagyszentmiklós als „Nachtisch-“ oder „Obstschälchen“ sind nicht stichhaltig. Dieses Schälchen ist nämlich zur Nahrungsmittelaufnahme zu klein; es konnten darin höchstens kleinere Beeren (Blaubeeren, Schlehen) oder Grütze hineingetan worden sein. Da das Schälchen aber nicht auf seinem Boden stehen kann, ist diese Behauptung ohne Gründen. Es kann darin auf keinen Fall Flüssigkeit eingefüllt und aufbewahrt worden sein, auch der größte Teil des angeführten Obstes oder jedweder Speise wäre ausgelaufen. Dieses Schälchen war also zum Einfüllen oder zum Verzehr jeglicher Nahrungsmittel ungeeignet.

${ }^{45}$ SZEKERES 1971, 84; NAGY 1972, 111-114, P1. 21.1; BÁlint 1989, 185, Abb. 83.1; LÁSZló-RÁCZ 1977, 147; BóNA 1984,
}

I, 344, II, 1600; WeRnER 1986, 36, 37, Abb. 5.1; M. Rusu: Tezaurul de la Sunnicolaul Mare. Noi puncte de vedere (Neue Gesichtspunkte hinsichtlich des Schatzes von Sînnicolaul Mare). AIIA 27 (1985/86) 48, 66, Pl. 3.3; idem: Le trésor de Vrap a-t-il appartenu au prince slave Acamir de Belzitia? In: M. Apostoloski (Hrsg.): Zbornik posveten na B. Babiḱ. Prilep 1986, 188, Fig. 1-1a. Der Autor oder der Graphiker letzteren Artikels hat nicht bemerkt, also die authentischen Erstpublikationen nicht gekannt, dass in der Henkelmitte des Schälchens ein Loch und kein kreisförmiges Verzierungselement ist: MRKOBRAD 1980, 103, Taf. CXLVIII.2.

${ }^{46}$ LÁSZLÓ-RÁCZ 1977, 147; WERNER 1986, 14-15, 35-38, 
werden können, kann man als es begründet ansehen, dass derzeit keine sicheren Angaben oder Hinweise zur Verfügung stehen, aufgrund dessen die Schalen von Vrap für awarische bzw. Produkte aus dem Karpatenbecken gehalten werden können. (Beide Autoren des vorliegenden Artikels befassten sich in anderen Arbeiten ausführlicher mit der Frage der awarischen Beziehungen des Fundes von Vrap. ${ }^{47}$ )

Die Schalen mit flachem Henkel aus Ada und die aus Nagyszentmiklós sind sowohl mit ovaler Form und auch mit gebogener Henkelform in der Awarenzeit einmalig. Dieser Gefäßtyp konnte sich nicht aus den awarenzeitlichen Vorläufern des 6.-7. Jahrhunderts entwickelt haben.

Entgegen allen Erwartungen wurden Schalen solcher Form aus diesen Jahrhunderten östlich der Karpaten nicht gefunden, die uns relevant wären. Sämtliche aus dem Kuban,$^{48}$ dem ehem. Gouvernement Poltava, dem Siebenstromland und aus der Ordos-Gegend ${ }^{49}$ bekannten Schalen sind rund bzw. annähernd rund. In typologischer Hinsicht stimmen sie also mit den Schalen No. 2, 3 und 4 von Vrap überein, aber alle sind aus späterer Zeit als diese und die aus Ada. ${ }^{50}$ Gleiches kann auch über die Form der Henkel gesagt werden. Die Henkel der erwähnten Schalen haben eselsrückenförmige, rankenverzierte, breite Henkel (manchmal befindet sich unter dem Henkel noch ein dünner Blechring). Die der beiden Schalen aus dem Karpatenbecken und die Schale Nr. 1 aus Vrap zeigen zweifellos eine vollkommene Formähnlichkeit, sie sind aber für unsere Forschung ebenfalls irrelevant, da diese aus wesentlich späterer Zeit stammen (11.-14. Jahrhundert). ${ }^{51}$

Es sind aber auch solche Henkel zum Aufhängen bekannt, deren Form diesen ähnlich ist, und in Zeit, Raum und kulturell einander sehr nahe stehen. Diese sind die eselsrückenförmigen Ösen zum Aufhängen der silberbeschlagenen Säbel aus der mittleren Awarenzeit. Sogar ihre Maßen weichen von denen aus Ada und Nagyszentmiklós nicht wesentlich ab (Schalenhenkel von Ada: L: 10,7 cm, B: $2,9 \mathrm{~cm}$, Schalenhenkel von Nagyszentmiklós: L: 12,3 cm, B: 3,1 cm; Säbelöse von Ozora: L: 8,7 cm, B: 4 cm, ${ }^{52}$ Säbelöse von Gyenesdiás, Grab 34: L: 9 cm, B: 3,6 $\left.\mathrm{cm}^{53}\right)$. Diese Ähnlichkeit wird durch die Münzbeigaben der Funde von Ozora und Gyenesdiás auch chronologisch unterstützt (Ozora: Konstantinos IV., 668-673, Gyenesdiás: Konstans II. - Konstantinos IV., 654-659), während die Öse der spätawarenzeitlichen Säbel einfach, länglich gebogen, d. h. unterschiedlich sind. ${ }^{54}$ Aufgrund dieser Analogien vermuten wir, dass die Schalen von Ada und Nagyszentmiklós typochronologisch nicht weit von den angeführten mittelawarenzeitlichen Funden stehen.

Nachdem ersichtlich ist, dass die Schalen von Ada, Nagyszentmiklós und von Vrap im Osten keine Analogie haben, überrascht es nicht, dass auch dort keine Parallelen für die Henkel gefunden wurden. Solche kommen in der römischen und byzantinischen Metallgefäßkunst vor. Dort ist es häufig, dass die runden oder ovalen Schälchen und Schalen einen den Gefäßrand breit umfassenden Henkel haben. Dieser Henkel ist in seiner einfacheren (frühen) Form eselsrückenförmig oder aber durch mehrere lappenartige Bogen unterteilt. Hier sind natürlich nicht die (spät)römerzeitlichen Exemplare ${ }^{55}$ von Interesse, sondern die der Zeit der aus Ada unbedingt näher stehenden byzantinischen Gefäße, die aus dem 6.-7. Jahrhundert stammen. Daraus folgt aber doch nicht eindeutig, dass Gefäße

${ }^{47}$ É. Garam: The Vrap treasure. In: K. R. Brown et al. (eds): From Attila to Charlemagne. Arts of the Early Medieval Period in the Metropolitan Museum of Art. New York 2000, 170-179; Cs. BÁLINT: Some Avar and Balkan connections of the Vrap treasure. In: ibidem 180-187.

${ }^{48}$ Novosvobodnaja-Fars 2, Kurgan 1, Grab 4, 14.-15. Jh. Grabschätze vom Kaukasus. Neue Ausgrabungen sowjetischer Archäologen in der Adygee und im nördlichen Ossetien. Hrsg. von A. Leskov-L. Noskova. Roma 1991, 63, Kat.-Nr. 296.

${ }^{49}$ Wujiadi (Provinz Xinghe), Grab 4, 13.-14. Jh.: A. T. KESSLER: Empires beyond the Great Wall. The heritage of Genghis Khan. Natural Museum of Los Angeles County 1993, 157, Fig. 103.

${ }^{50}$ Diesen Schälchen mit Henkel widmete die Forschung bisher wenig Aufmerksamkeit; zuletzt siehe WERNER 1986, 13-14, Taf. 7-9. Ausführlicher siehe BÁLINT 2005, 483-489.

${ }^{51}$ SMIRnOv 1909, Taf. XCVIII, CVIII, CXVII, CXXVIII.

${ }^{52}$ HAMPEL 1905, III, Taf. 268.12-13; É. GARAM: Katalog der awarenzeitlichen Goldgegenstände und der Fundstücke aus den Fürstengräbern im Ungarischen Nationalmuseum. Catalogi Musei Nationalis Hungarici, Seria archeologica [sic] 1. Budapest 1993, Taf. 75.23.
${ }^{53}$ R. MÜLLER: Vorbericht über die Freilegung des Grabes eines hohen Militärs aus der Awarenzeit in Gyenesdiás. ComArchHung 1989, 145, Abb. 4.3-4.

${ }^{54}$ Garam 1991, 149, Abb. 12, 151, Abb. 13, 154, Abb. 14. - Eine Ausnahme von dieser Tendenz bildet der mit dem Säbel von Ozora und dem von Gyenesdiás in die gleiche chronologische Gruppe eingereihte, aber nicht münzdatierte Säbel aus dem Fund von Igar, dessen Öse zum Anhängen nicht gleich den Vorigen eselsrückenförmig, sondern gleich den anderen länglich gebogen ist.

${ }^{55}$ Zum Beispiel A. RADNÓTr: Eine ovale Bronzeplatte aus Regensburg. BVb 30 (1965) 188-244; D. E. STRONG: Greek and Roman Gold and Silver Plate. London 1966, 146, Fig. 30; Trésors d'orfèvrerie gallo-romains. Ed. F. Baratte. Paris 1989, 8, No. 17, 94-95, No. 25, 101, No. 31, 153-154, No. 101 usw.; idem: La vaisselle d'argent dans l'Afrique romaine et byzantine. AntTard 5 (1997) 113-114, Fig. 3-5; Milano capitale dell'impero romano 286-402 d. C. Ed. A. Salvioni. Milano 1990, 176, No. 2h, 4c. 1, 274, No. 4e. 2d. 1; L. P. B. Stefanelli: L'argento dei Romani. Vassellame da tavola e d'apparato. Roma 1991, 162, Fig. 146. 
mit derartigen Henkeln aus dem 8. Jahrhundert überhaupt nicht mehr in Gebrauch waren, weil byzantinische Metallgefäße aus den 8.-9. Jahrhunderten fast vollkommen unbekannt sind.

Unter den byzantinischen Gefäßen ist hier als Erstes die aus dem meistens als Cherchel bezeichneten Patena (richtig: aus Cap Chenoua zwischen Cherchel und Tipasa in Algerien) zu erwähnen. Sein Henkel gibt den Gefäßrand bis fast zur Hälfte um, die beiden Enden stellen jeweils einen Greifenschnabel dar, was sich aus der Gesamtkomposition ergibt. Dieser Henkel folgt nicht einem einzigen, geraden Bogen, wie der der Schale von Ada, sondern er ist genauso gegliedert wie der von Nagyszentmiklós. Wie der Meisterstempel am Boden der Patena beweist, wurde diese zwischen 527 und 547, vermutlich in Konstantinopel angefertigt. ${ }^{56}$ Ein anderes Gefäß, das seines Henkels wegen für unsere Thema von Interesse ist, stammt aus der Kamagegend. Es wurde in der Fachliteratur nach seinem ersten Besitzer als Obolenskij-Trulla bezeichnet (wahrscheinlich in dem Dorf Pešnigort gefunden) und ist aufgrund den byzantinischen Stempeln nach E. Cruikshank-Dodd auf 527-565 datiert (nach L. A. Maculevič aus den zwanziger-dreißiger Jahren des 7. Jahrhunderts, nach A. Bank aus der Zeit zwischen 641 und 651). ${ }^{57}$ Die Henkelverzierung stimmt im Großen mit der der Patena von Cap Chenoua überein (Darstellung des Poseidon, einer Muschel, Delfine und Greifenköpfe), nur macht bei dieser der Bogen infolge der Komposition jeweils drei kleinere und größere Bogen. Ein drittes, ebenfalls aus dem mittleren Drittel des 7. Jahrhunderts stammendes Gefäß mit Stiel kam in dem Schatzfund von Kratygos, der durch einen von Phokas 609/610 und durch einen von Heraclius zwischen 613 und 616 geprägten Solidus datiert ist, ${ }^{58}$ zum Vorschein. Bei diesem schließt sich der Stiel mit je drei Halbkreisen an das Schälchen an.

Schon anhand dieser wenigen Angaben kann festgestellt werden, dass im 6.-7. Jahrhundert in der byzantinischen Welt selbst in voneinander sehr entfernten Gegenden derartige kleine Gefäße benutzt waren, deren Henkel gebogen ist und manchmal auch durch mehrere Pässe unterteilt einen größeren oder kleineren Teil des Randes umgibt. Aus dieser kurzen Übersicht erweist sich für die Schalen als wesentlich, dass weder deren Typ noch der breite Henkel aus der Steppe stammen können, ja sie können nicht einmal orientalischen Ursprungs sein. Man findet aber dieses Prinzip der Henkelgestaltung in dem römischen und byzantinischen Gefäßkunsthandwerk, darum muss dieser Henkel- und Gefäßtyp für byzantinischen Ursprungs gehalten werden. (Gleichzeitig mit dieser Behauptung soll unbedingt gesagt werden, dass typenmäßig auch der gebogene, dreipassartig gegliederte Henkel der Schale aus dem 8. Jahrhundert von Nagyszentmiklós denen aus der römischen und byzantinischen Zeit ähnlich ist. Letztere Schlussfolgerung bietet selbstverständlich keine unmittelbare chronologische Information den gesamten Schatz betreffend, kann aber in kulturellem Sinn auf alle Fälle orientierenden Wert haben.)

\section{SCHLUSSWORT}

Aus der Bearbeitung der aus Ada ins Museum gelangten Gegenstände erfolgt eine chronologische Bestimmung, die die früheren Überlegungen widerlegt. Die auf den Typ der Steigbügel und Gürtelbeschläge basierende, von Cs. Bálint vorgeschlagene Datierung („,erste Hälfte des 9. Jahrhunderts“), der die Steigbügel vom Typ Brodski Drenovac und die Gürtelbeschläge von Kiscsepcsény zugrunde lagen, ist nicht stichhaltig. Da der Fund von Ada gegenwärtig nicht genauer datiert werden kann, als in die zweite Hälfte der Spätawarenzeit, betrachten wir ihn ganz einfach als ein spätawarisches Fundensemble. So sind also die selteneren (schildförmiger Gürtelbeschlag mit einem waagerechten Glied in der Mitte und Steigbügel mit breiter, gerippter Sohle) und einmaligen Gegenstandstypen (Henkelschale) innerhalb dieser Periode zu bewerten. Dadurch fällt automatisch die Grundlage für die Schlussfolgerung, dass Ada der Beweis dafür sei, dass ,,in dieser Gegend auch nach den bulgarischen Einfällen und dem Auftreten der Südslawen noch awarische Krieger lebten und sich - was noch wichtiger ist - bestatten liessen“, weg. ${ }^{59}$

\footnotetext{
${ }^{56}$ Matzulewitsch 1929, 8, No. 15; Dodd 1961, No. 14.

${ }^{57}$ Matzulewitsch 1929, 6, No. 10, Taf. 12-15; DodD 1961, No. 77; A. BANK: Byzantine Art in the Collections of the USSR. Leningrad-Moscow 1965, No. 85-87.

${ }^{58}$ Siehe M. Andronicos-M. Chatzidakis-V. KaraGEORGHIS: Die Museen Griechenlands. Köln 1976, No. 28. - Die Be-
}

stimmung der Münzen nahm - auf unsere Bitte hin - Prof. W. Hahn anhand der Publikation vor, wofür wir ihm auch auf diesem Wege danken.

${ }^{59}$ Cs. BÁLINT: A Dél-Alföld a IX-X. században. Tiszatáj 1976/10, 34; idem 1989, 186. 
Wir sind uns selbstverständlich im Klaren darüber, dass es immer sehr riskant ist, Überlegungen darüber anzustellen, was wohl noch in dem Grab gewesen sein könnte. Aufgrund eines sozialpsychologischen Gesichtspunktes bzw. der allgemeinen Erfahrung der Feldarchäologen scheint allerdings die Annahme begründet zu sein, dass viele andere Gegenstände ursprünglich bereits nicht in das Grab gelangen konnten. Denn wenn die Finder eine so sehenswürdige und in der heutigen Welt noch „Nutzen bringende“, im illegalen Handel leicht abzusetzende Schale den Experten übergeben haben, dann konnte dort tatsächlich nicht mehr sehr viel gewesen sein. Wenn dieser Gedankengang richtig ist, bietet sich die Möglichkeit für zwei weitere Schlussfolgerungen. Beide stehen mit der Ähnlichkeit der Schale von Ada und der von Nagyszentmiklós im Zusammenhang, und beide Gegenstände bzw. Gegenstandsensembles weisen Lehren für die Forschung auf.

a) Der Besitzer der Schale von Ada kann allen Anzeichen nach überhaupt nicht so begütert gewesen sein, wie man lediglich aufgrund der Verwendung des Schalentyps von Nagyszentmiklós annehmen könnte. Anders ausgedrückt: der Schalentyp ist an sich nicht rangkennzeichnend.

b) Die Schale Nr. 8 von Nagyszentmiklós gehört zu einem Gefäßtyp, der (auch bzw. bereits) für ein Mitglied der Mittelschicht der awarischen Gesellschaft bekannt war. Das erlaubt die Annahme, dass eine chronologische und/oder kulturelle Verbindung zwischen den Besitzern dieses Fundtyps besteht.

Der Umstand, dass der Fund von Ada unanfechtbar awarischen Ursprungs ist, stellt einen grundlegenden Ausgangspunkt für die Erforschung des Schatzes von Nagyszentmiklós dar. Die Auswertung dieses Zusammenhangs ist die Aufgabe anderer, künftiger Arbeiten. ${ }^{60}$

KATALOG

Einige spätawarenzeitliche Zaumzeugbeschläge und deren Begleitfunde

\author{
A. Schildförmige Gürtelbeschläge mit unbeweglichem unterem Glied \\ 1. Blatnica, Streufund (aus mehreren Streufunden zusammengesetztes Fundensemble): rankenverzierte Riemenzunge, kreuzförmiger Verteiler, \\ Flügellanze mit länglicher Hakenöse, zweischneidiges Schwert, gegossener Phalerenknopf. FETTICH 1937, Taf. XCVII.14-20; XCVIII.14-20. \\ 2. Dubó, Streufund: Lochkranzbeschlag und kleiner Beschlag mit gepunzter Verzierung und Stabranke. Seoba naroda 1962, 16-17. \\ 3. Gadóc, Reitergrab 24: Mann: lilienverzierte Gürtelbeschläge mit graviert-gepunzter Verzierung; Pferd: rechteckige, schuppige Vierpassbe- \\ schläge, Riemenzunge mit Öse, Pferdestirnbeschlag, kugelabschnittförmiger Blechbeschlag. ČILINSKÁ 1982, 347-393. \\ 4. Gajár: gegossene Phalere, gegossene, rankenverzierte Nebenriemenzunge, kleiner Beschlag. FeтTich 1937, Taf. C.17-19. \\ 5. Komárom-Hajógyár, Reitergrab 1: Tongefäß. TRUGLY 1987, Taf. 1. \\ 6. Sremska Mitrovica, Streufund: Seoba naroda 1962, 95. \\ 7. Surduk, Streufund: Seoba naroda 1962, 96-97. \\ 8. Újvidék-Csene, Grab 2: Haupt- und Nebenriemenzunge (Letztere mit gepunzter Rankenverzierung), zweigliedriger Beschlag, fünf kleine \\ Beschläge, Klapper. Seoba naroda 1962, 53-54; MRKOBRAD 1980, Taf. CXXIII.7.
}

\title{
B. Riemenzungen mit kurzer Öse
}

1. Dunacséb, Pferdegrab 5: Beschlag mit Wildschweinkopf, graviert-gepunzter Vierpassbeschlag, rankenverzierter Lochanschützer. BUNARDžIĆ 1978, Taf. 1.

2. Dunacséb, Reitergrab 162: Mann: graviert-punzierte Gürtelzierden mit Lilienverzierung in Dreiergruppen; Pferd: gepresster, viereckiger Beschlag, Riemenzunge, schildförmiger Beschlag. BunARDžı́c 1985, Fig. 28.

3. Dunacséb, Grab 247: Vierpassbeschlag, Riemenzunge mit Öse, rechteckiger Beschlag. BunARDžlć 1985, Fig. 30.

4. Gajár: siehe unter $A 4$.

5. Kenyhec, Rreitergrab 100: Vierpassbeschlag, graviert-punzierter, rankenverzierter Lochanschützer. PASTOR 1968, 175-182, Abb. 3.12-14.

6. Kaposvár, Reitergrab 14: Mann: rankenverzierte Gürtelbeschläge, Beschläge in Dreiergruppen; Pferd: Beschlag mit Wildschweinkopf, Vierpassbeschläge.

7. Komárom-Váradi utca, Reitergrab 25: rankenverzierte Nebenriemenzunge, Vierpassbeschlag, rechteckiger Beschlag, kugelabschnittförmiger Beschlag. ČILINSKÁ 1982, 18-22, Taf. XI.8.

${ }^{60}$ Idem 2005. 
8. Mikulčice: Z. KLANICA: Vorgroßmährische Siedlung in Mikulčice und ihre Beziehungen zum Karpatenbecken. ŠtZ 16 (1968) 123, Abb. 1.9. 9. Szob, Reitergrab 90: Mann: rankenverzierter Doppelblech- und schildförmiger, rankenverzierter Beschlag; Pferd: runder, gepresster Beschlag, Trense mit Seitenstangen, Steigbügel, Gefäß. KovRIG 1975, Fig. 10.31-32.

10. Toponár, Pferdegrab 52: gegossener, runder Beschlag, Pferdestirnbeschlag. SzENTPÉTERI 1993, 57, Abb. 10.

C. Große, schildförmige Beschläge mit durchbrochenem unteren Glied

1. Biatorbágy, Grab 264: männliches Reitergrab: Gürtelgarnitur, Pferdegeschirr und -beschläge. L. SIMON: Köpakolásos temetkezések a biatorbágyi avar temetőben (előzetes jelentés) (Steinpackungsbestattungen in dem awarischen Gräberfeld von Biatorbágy [Vorbericht]). HOMÉ 30-31/2 (1993) 155, Fig. 14.5-6.

2. Dévényújfalu, Reitergrab 759: Mann: rankenverzierte Hülsenriemenzunge, Gefäß; Pferd: rechteckiger Beschlag. EISNER 1952, Fig. 81.4.

3. Kenyhec: siehe $B 5$.

4. Kaposvár, Reitergrab 14: siehe B6.

5. Komárom-Hajógyár, Reitergrab 12: Riemenzunge mit Mensch- und Löwendarstellung, Schlaufe mit graviert-punzierter Verzierung an der Seite, Gürtelbeschlag mit Adler. TRUGLY 1987, Taf. III, IV.

6. Komárom-Hajógyár, Reitergrab 79: Mann: lilienverzierte Riemenzunge, Beschlag in Dreiergruppierung, graviert-punzierte Zierde, Pferd: kugelabschnittförmiger Beschlag, kurze Riemenzunge, Pferdestirnbeschlag. TRUGLY 1987, Taf. XXI, XXII.

7. Komárom-Hajógyár, Reitergrab 85: Mann: schildförmiger, löwenverzierter Beschlag; Pferd: Hutphalere, gepresster, graviert-punzierter, kugelabschnittförmiger Beschlag, Blechriemenzunge. TRUGLY 1987, Taf. XXVII, XXVIII.

8. Komárom-Hajógyár, Reitergrab 87: Mann: rankenverzierte Hauptriemenzunge aus Doppelblech, schildförmiger, rankenverzierter Beschlag; Pferd: Vierpassbeschlag. TRugly 1987, Taf. XXIX, XXX.

9. Komárom-Váradi utca, Grab 25: s. B7.

10. Mikulčice-Kostelec: L. PoláčEK: Mikulčice im 8. Jahrhundert. In: F. Daim (Hrsg.): Reitervölker aus dem Osten. Hunnen und Awaren. Halbturn 1996, 331, rechts unten.

11. Mikulčice: glattes, unverziertes Bronzegussstück guter Qualität. Z. KLANICA: Vorbericht über die Grabungsergebnisse des altslawischen Burgwalles in Mikulčice für das Jahr 1964. PV 1964 (1965) Taf. 25.10.

12. Novi Banovci, Streufund: Seoba naroda 1962, 87; MRковRAD 1980, Taf. CXX.1.

13. Vágsellye II, Reitergrab 83: rankenverziertes Gürtelgelenk, Phalere, graviert-punzierter Blechstirnschmuck. ČILINSKÁ 1963, 533, Fig. 4.29. 14. Sremska Mitrovica: siehe A6.

15. Surduk, Streufund: MrKoBRAD 1980, Taf. CXIX.15.

D. Längliche Riemenzungen

1. Dunacséb, Pferdegrab 5: siehe B1.

2. Dunacséb, Reitergrab 162: siehe $B 2$.

3. Gadóc, Rreitergrab 24: siehe $A 3$.

4. Gajár: siehe $A 4$.

5. Komárom-Hajógyár, Reitergrab 1: siehe A6.

6. Komárom-Hajógyár, Reitergrab 12: siehe C5.

7. Komárom-Hajógyár, Reitergrab 87: siehe $C 8$.

8. Kövágószőlös, Pferdegrab A, B und Streufund: Mann: Gürtelbeschläge mit Schuppenmuster, graviert-punzierte Zierde; Pferd: dreieckiger Zaumzeugbeschlag, graviert-punzierte Zierde, Riemenzunge. KIss 1977, Pl. XXV.6; NAGY 1983, Bild 3.4-5; Bild 5.2-3.

9. Lukácsháza: Gürtelbeschläge vom Typ Vrap. G. Kiss: A lukácsházi avar lovassír. Savaria Múzeum Kiállítási Lapok 1. Szombathely 1988; idem 1996.

10. Toponár, Pferdegrab 52: siehe B10.

E. Kugelabschnittförmige Zaumzeugbeschläge

1. Gajár: siehe $A 4$.

2. Vágsellye II, Grab 83: ČILINSKÁ 1963, 533, Fig. 4.28.

3. Szob, Grab 90: siehe B9.

4. Vörs-Papkert, Reitergrab 352: MÜLLER 1990, Abb. 14.

5. Zalakomár-Lesvári-düló, Grab 150: Zwillingsperle, gedreht endender Ohrring mit Blechanhänger. Freundliche mündliche Mitteilung von B. M. Szőke.

Acta Archaeologica Academiae Scientiarum Hungaricae 67, 2016 


\section{F. Steigbügel mit gerader und breiter Sohle}

1. Brodski Drenovac, Reitergrab 14: Trense mit S-förmiger Seitenstange, Säbel, Gefäß. VinSKI-GASPARINI-ERCEGOVIĆ-PAVLOVIĆ 1958, Taf. XIV.

2. Debrecen-Ondód, Pferdegrab 2: Trense mit S-förmiger Seitenstange, Vierpassbeschlag. L. ZoLTAI: Jelentés Debrecen szabad királyi város múzeumának 1925. évi működéséről és állapotáról. Jelentés a Déri Múzeum állapotáról. Debrecen 1926, 4-9.

3. Dunacséb, Reitergrab 162: siehe B2.

4. Érsekújvár (Massen)Grab 139: ovaler Ohrring mit Prismaanhänger. ČılinsKá 1966, 31, Taf. XXXI.4.

5. Gadóc, Reitergrab 15: Pferd: rankenverzierter Beschlag mit gebogenen Seiten, Gefäß, eisernes Messer. ČILINSKÁ 1982, Taf. XIV.

6. Gadóc, Reitergrab 24: siehe A3.

7. Komárom-Hajógyár, Reitergrab 87: siehe C8.

8. Kövágószölös: siehe $D 9$.

9. Lukácsháza: siehe D10.

10. Orosháza-Bónum, Pferdegrab L: Säbelfragment, Sargklammer. JuHÁsz 1995, Taf. 15.

11. Szirák, Reitergrab 38: Mann: Beschläge in Dreiergruppen, graviert-punzierte Zierde; Pferd: Trense mit S-förmige Seitenstange. HAMPEL 1905, III, Taf. 68.1-2.

12. Zagreb-Kruge, Reitergrab 4: rankenverzierte Hauptriemenzunge, Schnalle mit Blechkörper, Sax, Trense mit Seitenstange, Sattelbogeneisen, „Knüpfer“. VINSKi 1960, 14, S1. 27-31.

13. Zsitvatö, Pferdegrab 7: Trense mit Seitenstange, runde Blechphalere mit gepresstem Mittelteil. BUDINSKÝ-KRIČKA 1956, Taf. XIV.7.

14. Bogaljevci, Streufund: Z. BoJČıć: Pregled istraživanja i rasprostranjenosti ranosrednjovekovnih arheoloških nalaza v istočnoj Slavoniji i Baranji (Archaeologische Forschungen in Ostslawonien und Baranja). In: Arheološka istraživanja u istočnoj Slavoniji i Baranji. Zagreb 1984, 216, Fig. 2E.

\section{OFFIZIELLE BEZEICHNUNG DER IN UNGARISCHER FORM VERWENDETEN ORTSNAMEN}

Dévényújfalu = Devínska Nová Ves, Slowakei

Dubó = Dubovac, Serbien

Dunacséb $=$ Čelarevo, Serbien

Érsekújvár = Nové Zámky, Slowakei

Gadóc $=$ Komárno-Hadovce, Slowakei

Gajár = Gajáry, Slowakei

Kassazsebes $=$ Šebastovce, Slowakei

Kenyhec $=$ Hraničná pri Hornáde, Slowakei

Komárom-Hajógyár = Komárno-Lodenice, Slowakei

Komárom-Váradi utca = Komárno-Váradiho ulica, Slowakei

Rigómező = Kosovo Polje, Serbien

Újvidék = Novi Sad, Serbien

Vágsellye = Sal'a, Slowakei

Zsitvatő = Žitavská Tôn, Slowakei

\section{LITERATUR}

BÁLINT 1979

BÁLINT 1989

BÁLINT 2005

BÁRDOS 1978

BENDE 1998

BÓNA 1971
= Cs. BÁLINT: Les selles hongroises de $\mathrm{X}^{\mathrm{e}}$ siècle et rapports orientaux. Türk Kültürünü Araştirma Entitüsü 51/I, A7. Ankara 1979, 1-49.

= Cs. BÁLINT: Die Archäologie der Steppe. Wien-Köln-Graz 1989.

= Cs. BÁLINT: A note on the research on the ewer with enamel plaques of St. Maurice d'Agaune. ActaArchHung 56 (2005) 281-289.

= E. BÁRDOs: Avar temetö Kaposvár határában (Rescue excavation on the findspot Nr. 33 of Kaposvár). SMK 3 (1978) 13-65.

= L. BENDE: A pitvarosi késő avar kori temető 51. sírja. Adatok a késő avar kori lószerszámok díszítéséhez (Das Grab 51 im spätawarenzeitlichen Gräberfeld in Pitvaros. Beiträge zur Verzierung der spätawarenzeitlichen Pferdegeschirrs). MFMÉ 4 (1998) 195-230.

= I. BÓNA: Ein Vierteljahrhundert Völkerwanderungszeitforschung in Ungarn (1945-1969). ActaArchHung 23 (1971) 265-336. 
BÓNA 1984

BÓNA 1994

BUDINSKÝ-KRIČKA-TOČÍK 1991

BUNARDŽIĆ 1979

BuNARDŽIĆ 1985

Cemeteries 1975-1995

ČILINSKÁ 1963

ČILINSKÁ 1966

ČILINSKÁ 1982

DAIM 1987

DARKEVIČ 1976

DODD 1961

EISNER 1952

FETTICH 1937

FETTICH 1943

GARAM 1976

GARAM 1981

GARAM 1984

GARAM 1991

\section{GARAM 1995}

GenING-Chalikov 1964 GYÖRFFY-ZÓLYOMI 1994

HAMPEL 1905

Honfoglalás 1994

JoTOV 1987

JUHÁSZ 1992

JUHÁSZ 1995

KADA 1906

KENK 1982

KIRPIČNIKOV 1966

KISS 1977

KISs 1996

KISs 1996

KOVRIG 1963

KOVRIG 1975

KOVRIG-KoreK 1960
= I. BóNA: A népvándorlás kor és korai középkor története Magyarországon. In: A. Bartha (Hrsg.): Magyarország története. I: Előzmények és magyar történet 1242-ig. Budapest 1984, 265 - 373; 1586-1606.

= I. BónA: Az Avar Birodalom végnapjai. Viták és új eredmények. In: Honfoglalás 1994, 67-75.

= V. BuDINSKÝ-KRIČKA-A. TočíK: Šebastovce. Gräberfeld aus der Zeit des awarischen Reiches. Nitra 1991.aaaa

$=$ R. BUnARDŽIĆ: Izveštaj sa zaštitnog arheološkog iskopavanja ranosrednjovekovne nekropole na lokalitetu „Ciglana“ kod Čelareva (Report on the protective archaeological excavation of the medieval necropolis at the "Ciglana” locality near Čelarevo). Gradja za Proučvanje Spomenika Kulture Vojvodine 8-9 (1978-1979) 33-67.

= R. BunARDŽIĆ: Čelarevo. Risultati delle ricerche nelle necropoli dell'alto medioevo. Roma 1985.

= I. Kovrig (Hrsg.): Cemeteries of the Avar Period (567-829) in Hungary. Budapest 1975-1995.

= Z. ČILINSKÁ: Dve predvel'komoravské pohrebiska v Šali, okr. Galanta (Zwei vorgroßmährische Gräberfelder in Šala, Kr. Galanta). AR 25 (1963) 527-538.

= Z. ČILINSKÁ: Slawisch-awarisches Gräberfeld in Nové Zámky. ASF 7. Bratislava 1966.

= Z. ČILINSKÁ: Dve pohrebiská z 8-9. storočia v Komarne (Zwei Gräberfelder aus den 8.-9. Jh. in Komárno. Dva mogil'nika VIII-IX vv. v g. Komarno). S1A 30 (1982) 347-393.

= F. DAIM: Das awarische Gräberfeld von Leobersdorf, NÖ. Denkschriften der Österreichischen Akademie der Wissenschaften, Phil.-Hist. Klasse 194. Studien zur Archäologie der Awaren 3/1. Wien 1987.

= V. P. DARKEvič: Chudožestvennyj metall Vostoka VIII-IX vv. Moskva 1976.

= E. C. DODD: Byzantine Silver Stamps. Dumbarton Oaks Studies 7. Washington D.C. 1961.

= J. EISNER: Devinská Nova Ves. Bratislava 1952.

= N. FETTich: Die Metallkunst der landnehmenden Ungarn. ArchHung 21. Budapest 1937.

= N. FetTich: Győr a népvándorláskorban. Győr 1943.

= É. GARAM: Adatok a középavarkor és az avar fejedelmi sírok régészeti és történeti kérdéséhez ( $\mathrm{Zu}$ den archäologischen und historischen Fragen der mittleren Awarenzeit und der awarischen Fürstengräber). FolArch 27 (1976) 129-145.

= É. GARAM: A bőcsi lelet és köre (Pozdneavarskie vešči iz g. Beči ich analogii - Der spätawarenzeitliche Fund von Böcs und sein Kreis). ArchÉrt 108 (1981) 34-51.

= É. GARAM: Spätawarenzeitliche Goldgegenstände im Ungarischen Nationalmuseum. FolArch 35 (1984) 87-108.

= É. GARAM: A Tiszakécske-óbögi avarkori sírok. Adatok az avarkori szablyákhoz és az egyenes, egyélü kardokhoz (Awarenzeitliche Gräber von Tiszakécske-Óbög. Angaben zu den Säbeln und den geraden einschneidigen Schwertern der Awarenzeit). ComArchHung 1991, 129-163.

= É. GARAM: Das awarenzeitliche Gräberfeld von Tiszafüred. Cemeteries 1975-1995, 3. Budapest 1995.

= V. F. Gening-A. Ch. Chalikov: Rannye bolgary na Volge. Moskva 1964.

= Gy. GYÖRFFY-B. ZólYOMI: A Kárpát-medence és Etelköz képe egy évezred előtt. In: Honfoglalás 1994, 13-39.

= J. HAMPEL: Alterthümer des frühen Mittelalters in Ungarn. I-III. Braunschweig 1905.

= L. Kovács (Hg.): Honfoglalás és régészet. A honfoglalásról sok szemmel 1. Budapest 1994.

= V. Jotov: Četiri železni stremena ot starobălgarskoto selišče pri s. Božurovo, Tolbuhinski okrăg. Dobrudža 4 (1984) 93-95.

= I. JuHÁsz: Szarvas-Rózsás. RégFüz 44 (1992) 51.

= I. JUHÁsz: Awarenzeitliche Gräberfelder in der Gemarkung Orosháza. MAA 1. Budapest 1995.

= E. KADA: Gátéri temető a régibb középkorból (Gräberfeld von Gátér aus dem frühen Mittelalter). ArchÉrt 26 (1906) 135-155, 207-221.

= R. KENK: Früh- und hochmittelalterliche Gräber von Kudyrgè im Altai. Frühmittelalterliche Gräber aus West-Tuva. AVA-Materialien 3-4. München 1982.

= A. N. KIRPIČNIKOv: Drevnerusskoje oružie. I. Svod Archeologičeskich Istočnikov E1-36. Moskva 1966.

= A. KISs: Avar Cemeteries in County Baranya. Cemeteries 1975-1995, 2. Budapest 1977.

= A. KISS: Das awarenzeitliche gepidische Gräberfeld von Kölked-Feketekapu A. Monographien zur Frühgeschichte und Mittelalterarchäologie 2. Innsbruck 1996.

= G. KISS: A lukácsházi avar temető 8. számú lovas sírja. A késő avar tausírozott vasfalerák (Reitergrab 8 des awarenzeitlichen Gräberfeldes Lukácsháza-Hegyalja-dűlő). Savaria 22/3 (1996) 107-143.

= I. KOVRIG: Das awarenzeitliche Gräberfeld von Alattyán. ArchHung 40. Budapest 1963.

= I. Kovrig: The Avar cemetery from Dévaványa, Tiszaderzs, Szob. In: Cemeteries 1975-1995, 1. Budapest 1975, 121-155.

= I. Kovrig-J. KoreK: Le cimetière de l'époque avare de Csóka. ActaArchHung 12 (1960) 257-297. 
KRIGANOV 1987

LÁSZLÓ 1938

LÁSZLÓ 1955

LÁSZLÓ-RÁCZ 1977

Marosi-FetTich 1936

MARŠAK 1961

MaRsCHAK 1986

MATZULEWITSCH 1929

MRKOBRAD 1980

MÜLLER 1990

NAGY 1983

NAGY 1972

PASTOR 1968

Pletnëva 1989

Seoba naroda 1962

SMIRNOV 1909

STEIN 1967

SZATMÁRI 1985

SZEKERES 1971

SZENTPÉTERI 1993

TóTH-HoRVÁth 1992

TRUGLY 1987

TRUGLY 1993

VINSKI-GASPARINI-ERCEGOVIĆPAVlović 1958

VINSKI 1960

WERNER 1986

ZOLL-ADAMIKOWA 1992
= A. V. KRIGANOV: Kisteni saltovo-majackoj kultury Podonja (Bludgeons of the Saltovo-Mayak culture in the Don basin). SA 1987/2, 63-69.

= GY. LÁszló: Adatok a koronázási jogar régészeti megvilágításához. In: J.Serédi (Hrsg.): Szent István emlékkönyv. Budapest 1938, 771-810.

= Gy. LÁszLó: Études archéologiques sur la société des Avars. ArchHung 34. Budapest 1955.

= Gy. LÁsZLó-I. RÁCZ: Der Schatz von Nagyszentmiklós. Budapest 1977.

= A. Marosi-N. Fettich: Trouvailles avares de Dunapentele. ArchHung 18. Budapest 1936.

= B. I. MARŠAK: Vlijanie torevtiki na sogdijskuju keramiku VII-VIII vv. TGE 5. Leningad 1961.

= B. I. MarschaK: Silberschätze des Orients. Leipzig 1986.

= L. Matzulewitsch: Byzantinische Antike. Studien auf Grund der Silbergefäße der Ermitage. Archäologische Mitteilungen aus russischen Sammlungen II. Berlin-Leipzig 1929.

= D. MRKoBRAD: Arheološki nalazi seobe naroda u Jugoslaviji (Archäologische Funde der Völkerwanderungszeit in Jugoslawien). Fontes Archaeologiae Iugoslaviae 3. Monografije 6. Beograd 1980.

= R. MüLleR: Der Häuptling von Gyenes. In: Die Awarenzeit in der Umgebung von Keszthely. Ausstellungskatalog. Kataloge des Niederösterreichischen Landesmuseums N.F. 256. Wien 1990.

= E. NAGY: Újabb későavarkori temetők Baranya megyében (New cemeteries from the Late Avar Period in County Baranya). JPMÉ 27 (1983) 125-141.

= S. NAGY: Le cimetière de Verbas de l'époque avare et ses rapports avec le trésor de Nagyszentmiklós et la tasse argent d'Ada. In: L. Gerevich (ed.): Les questions fondamentales du peuplement du bassin des Carpathes des VIII ${ }^{\mathrm{e}}$ au X ${ }^{\mathrm{e}}$ siècles. MittArchInst Beiheft 1. Budapest 1972, 11-114.

= J. PASTOR: Skelettgräberfelder aus dem VII. und VIII. Jahrhundert in der Ostslowakei. ŠtZ 16 (1968) 175-182.

= S. A. PletnËVA: Na slavjano-chazarskom pogranič'e. Dmitrievskij archeologičeskij kompleks.

= D. Dimitriević-J. KovačEvić-Z. Vinski: Seoba naroda. Arheološki nalazi jugoslovenskog Podunavlja. Zemun 1962

= JA. I. SmiRnov: Vostočnoe serebro. Atlas drevnej serebrajnoj i zolotoj posudy vostočnago proischoždenija, najdennoj preimuščestvenno v predelach Rossijskoj imperii. Sanktpeterburg 1909.

= F. STEIN: Adelsgräber des achten Jahrhunderts in Deutschland. Germanische Denkmäler der Völkerwanderungszeit Serie A 9. Berlin 1967.

= S. B. SzATMÁRI: Komárom megye avarkori leletei. A Tatabánya-alsógallai avar temető és telepásatás. Régészeti kutatások a Dunántúlon 4. Székesfehérvár-Tata 1985.

= L. SzEKERES: Zenta és környéke a régészeti leletek tükrében. Senta 1971.

= J. SzENTPÉTERI: Egy késő avar kori lovas tiszti jelvény - a „csótár“ (Ein spätawarenzeitliches Kavallerieoffizierzeichen - die Kopfbuschhülse). In: G. Lőrinczy (Hrsg.): Az Alföld a 9. században. Szeged 1993, 49-77.

= E. H. Tóth-A. HoRvÁth: Kunbábony. Das Grab eines Awarenkhagans. Kecskemét 1992.

= A. TRugly: Gräberfeld aus der Zeit des awarischen Reiches bei der Schiffswerft in Komárno. S1A 35 (1987) 251-344.

= A. TRugly: Gräberfeld aus der Zeit des awarischen Reiches bei der Schiffswerft in Komárno. II. S1A 41 (1993) 191-352.

= K. S. VINSKI-GASPARINI-S. L. ERCEGOVIĆ-PAVlović: Rano-srednjovjekovno groblje u Brodskom Drenovcu (Das frühmittelalterliche Gräberfeld von Brodski Drenovac). VAMZ 3 (1958) 129-161.

$=$ Z. VINSKI: Ranosrednjevekovni arheološki nalazi na uzem i širem području Zagreba német cím. Iz Starog i Novog Zagreba 2 (1960) 47-65.

= J. WERnER: Der Schatzfund von Vrap in Albanien. Denkschriften der Österreichischen Akademie der Wissenschaften, Phil.-Hist. Klasse 184. Studien zur Archäologie der Awaren 2. Wien 1986.

= H. Zoll-Adamikowa: Zur Chronologie der awarenzeitlichen Funde aus Polen. In: K. Godłowski-R. Madyda-Legutko (Hrsg.): Probleme der relativen und absoluten Chronologie ab Latènezeit bis zum Frühmittelalter. Kraków 1992. 